\title{
A three-dimensional elastic-plastic damage model for predicting the impact behaviour of fibre-reinforced polymer-matrix composites
}

\author{
Haibao Liua, Jun Liua, Yuzhe Dinga, Zoe E. Halla, Xiangshao Konga, b, Jin Zhouª, \\ Bamber R.K. Blackmana, Anthony J. Kinlocha, *, John P. Deara, * \\ ${ }^{a}$ Department of Mechanical Engineering, Imperial College London, London SW7 2AZ, United Kingdom \\ ${ }^{b}$ Departments of Naval Architecture, Ocean and Structural Engineering, School of Transportation, Wuhan University of \\ Technology, Wuhan, Hubei 430063, People's Republic of China. \\ 'S School of Mechanical Engineering, Xi'an Jiaotong University, Xi'an, Shaanxi 710049, People's Republic of China
}

\footnotetext{
* Correspondence to: Prof Anthony J. Kinloch (a.kinloch@imperial.ac.uk) and Prof John P. Dear (j.dear@imperial.ac.uk)
}

\section{ABSTRACT}

A three-dimensional (3-D) Finite Element Analysis (FEA) model incorporating an elastic-plastic (EP) damage model, which was implemented as a user-defined material ('VUMAT') sub-routine in a FEA code ('Abaqus/Explicit'), is developed to simulate the impact response of carbon-fibre reinforcedplastic (CFRP) composites. The model predicts the load versus time and the load versus displacement responses of the composite during the impact event. Further, it predicts the extent, shape and direction of any intralaminar damage and interlaminar delaminations, i.e. interlaminar cracking, as a function of the depth through the thickness of the impacted CFRP test specimen, as well as the extent of permanent indention caused by the impactor striking the composite plate. To validate the model, experimental results are obtained from relatively low-velocity impact tests on CFRP plates employing either a matrix of a thermoplastic polymer, i.e. poly(ether-ether ketone), or a thermosetting epoxy polymer. The 3-D EP model that has been developed is shown to model successfully the experimentally-measured impact behaviour of the CFRP composites.

Keywords: Polymer-matrix composites (PMCs); Impact behaviour; Damage mechanisms; Computational mechanics; Elastic-plastic properties; 


\section{Introduction}

With low-carbon emissions in mind, modern manufacturing industries are showing an increasing interest in lightweight materials for transport applications and very good candidates are fibre-reinforced polymer-matrix composites. These materials have demonstrated relatively high stiffness-to-weight and strength-to-weight ratios, as well as good fatigue and corrosion resistance, compared with more traditional metallic materials. However, such composite materials suffer from being susceptible to impact damage, which may not be readily visible, but can lead to a significant loss of structural integrity. Thus, accurate models for assessing the damage suffered by fibrereinforced polymer-matrix composites upon being impacted by a foreign object would clearly be of great assistance to design engineers. It is intended that the model described in the present paper will, in the future, be used to predict the impact behaviour of carbon-fibre reinforced-plastic (CFRP) composites that have been damaged and then repaired using adhesively-bonded CFRP patches. It has, therefore, been formulated with this ultimate use in mind. However, clearly, the first step is to validate the new model by comparing the results from the modelling predictions to experimental results obtained from impacting a relatively simple geometry, i.e. a basic CFRP plate, at a relatively low-velocity and this is the subject of the present paper.

Numerical models are particularly useful when trying to represent reality more closely and should also lead to a better understanding of the impact behaviour of composite laminates. Hence, there have been a number of papers [e.g. 1-22] on developing finite-element analysis (FEA) models to simulate the impact behaviour of fibre-reinforced polymer-matrix composites, especially for CFRP composites struck by a rigid impactor at a relatively low-velocity of typically between about 1 to 15 $\mathrm{m} . \mathrm{s}^{-1}$, with a corresponding impact energy of between about 2 to $25 \mathrm{~J}$. The major damage mechanisms observed when a CFRP composite is impacted at a relatively low-velocity are: (a) intralaminar damage which typically involves plastic deformation of the matrix, matrix cracking, fibre debonding and localised fibre failure and (b) interlaminar damage which typically involves the initiation and growth of delaminations, i.e. interlaminar cracking, between the layers that form the composite laminate. These two main damage mechanisms are interactive during the impact event. In the numerical models, to simulate the impact event and the behaviour of the impacted CFRP composite, the usual overall methodology is to combine continuum damage models with a fracture-mechanics approach, which are embedded in a commercial FEA software package. 
For example, in previous work Liu et al. [21,22] have used a typical two-dimensional (2-D) elastic model which was implemented in an FEA code for predicting the impact behaviour of CFRPs. The initiation of intralaminar damage in the fibre-reinforced composites was captured using the Hashin damage approach $[23,24]$ and its evolution was defined via a continuum damage mechanics approach [25]. The initiation of interlaminar damage in the CFRPs was captured using a quadratic stress criterion [26] and the evolution of the interlaminar damage was modelled using a linearsoftening material model embedded into a bilinear cohesive law $[25,27,28]$ which was implemented as interface elements placed between the plies $[25,29,30]$. The area under the bilinear cohesive law was equated to the measured interlaminar fracture energy, allowing for mode-mixity effects [30-32]. Thus, a fracture mechanics approach provided the basic criterion for delamination, i.e. interlaminar cracking, to occur. This 2-D elastic damage model has been found $[21,22]$ to give good agreement with such parameters as the experimentally-measured impact load and the overall delamination areas for several different CFRP materials. However, it cannot take into account any plastic deformation of the composite material prior to the initiation of damage. Further, since it is only a 2-D model, it therefore cannot accommodate a three-dimensional (3-D) stress-state. Thus, the above 2-D elastic damage model lacks the ability to characterise fully the damage in the composite and it cannot predict the detailed shape and direction of the areas of delamination between the plies of the composite laminate. The aim of the present paper is to address these shortcomings and to validate a 3-D elasticplastic (EP) model then can subsequently be employed, with confidence, to predict the impact response of damaged CFRP plates that have been repaired using adhesively-bonded CFRP patches.

Now, considering the modelling of the low-velocity impact on fibre-reinforced polymer-matrix composites and composite structures, some of the more relevant prior work is that of Sun and Hallett [16] who developed a 3-D composite damage model, which incorporated non-linear deformations and contacts, to predict the impact behaviour of composite components subjected to a low-velocity impact loading. Also, Donadon et al. [4] and Shi et al. [10,13] have developed 3-D models which have incorporated non-linear material behaviour via a semi-empirical expression $[33,34]$ to represent the shear response. Also, for more complex structures, Faggiani and Falzon [7] have employed a 3-D damage model which again incorporated the non-linear shear behaviour to predict the impact damage in a stiffened composite plate. We have adopted a somewhat different approach in the current paper and have used the 3-D EP model proposed by Sun et al. [35,36]. Firstly, it has been reported [37] that this is a relatively simple and accurate model to incorporate into a continuum damage model based 
on a FEA approach. Secondly, the Sun et al. $[35,36]$ model can account for the anisotropy in the plastic behaviour of the composite and, in the present model, the plastic behaviour in the tensile, compressive and shear directions are considered. This may lead, therefore, to a more accurate representation of the permanent indentation caused when the impactor strikes the CFRP plate. Thirdly, the current model is designed to be used for predicting the impact behaviour of adhesivelybonded repaired CFRP plates. In such composite structures the adhesive layer, typically based upon a rubber-toughened epoxy polymer, is highly ductile and can be most accurately described by the Sun et al. $[35,36]$ EP model. Another important feature of any such FEA damage model is the criteria used to determine the onset of the initiation of intralaminar damage such as matrix cracking, etc. The present model employs the Northwestern University (NU) 3-D failure criteria, which mainly focus on transverse and through-thickness matrix failure under tension, compression and shear stresses, as developed by Daniel et al. [38-40]. The NU failure criteria have been shown to give accurate predictions of multiaxial failure conditions in polymer-matrix composites $[41,42]$ and are readily applicable to both multidirectional composite ply lay-ups $[39,40,43,44]$ and woven composite plies [38$40,45]$. It should be noted that alternative such criteria favoured by many leading researchers are given by the Puck [46] model. However, the Puck model requires additional information, e.g. the orientation of the matrix cracking, and such additional fitting parameters need to be determined experimentally to give the model a good predictive capability [42]. Thus, the Puck model is not really appropriate for woven composite materials. It was therefore considered that the NU failure criteria are more relevant to an FEA model aimed at predicting the impact response of repaired CFRP plates when woven composites are to be employed along with multidirectional composites.

Therefore, in the present paper, the previous 2-D elastic model developed by Liu et al. $[20,21]$ is extended to give a 3-D EP FEA model to predict the behaviour of CFRP composites subjected to a low-velocity impact. This is achieved by modelling the 3-D EP behaviour of the composite material by incorporating the equivalent stress versus equivalent plastic strain relationships proposed by Sun et al. $[35,36]$. These relationships are defined by a power-law and are based upon a 3-D yield function that is quadratic in stress, as discussed in detail below and in Appendix A. This approach defines the stress components and anisotropic plastic strain components in different directions and is able to very readily, and accurately, accommodate a 3-D stress-state and the EP response of the composites. This equivalent stress versus equivalent plastic-strain relation is introduced into the FEA code ('Abaqus/Explicit') via a user-defined material ('VUMAT') sub-routine. The present model employs the 
3-D NU failure criteria [38-40] to determine the initiation of intralaminar damage such as matrix cracking, etc. This combination of features in the proposed 3-D elastic-plastic (EP) FEA damage model actually represents a novel approach and clearly first needs to be validated against experimental data. This is the main aim of the present paper where the results from the 3-D EP damage model are validated by a comparison with detailed experimental results on the impact behaviour of thermoset- and thermoplastic-matrix CFRP composites subjected to a low-velocity impact by a rigid projectile.

\section{Experimental}

Unidirectional 'AS4' carbon-fibre reinforced poly(ether-ether ketone) (CF/PEEK) prepregs, supplied by Solvay, Belgium, and unidirectional 'T700' carbon-fibre reinforced epoxy (CF/Epoxy) prepregs, supplied by AVIC Composite Corporation, China, were used to fabricate large flat plates of the thermoplastic-matrix and thermoset-matrix composite laminates, respectively, which were cut into the smaller test specimens. These test specimens were prepared using a lay-up of $\left[0_{3} / 90_{3}\right]_{2 s}$, with the $0^{\circ}$ plies laid along the longer dimension of the rectangular specimens, as shown schematically in Fig. 1, and the specimens possessed a nominal thickness of $3.0 \mathrm{~mm}$. In Fig. 1, X-Y-Z refer to the global coordinate system and, correspondingly, the material coordinate system was defined as $1-2-3$. The manufacturing details for these carbon-fibre reinforced-plastic (CFRP) specimens have been given previously [22,47]. Low-velocity impact tests on the CFRP specimens were undertaken and these have also been described in detail elsewhere [22,47]. Essentially, an 'Instron 9340' drop-tower (CEAST, Italy), was used with an instrumented stainless-steel impactor having a hemisphericallyshaped head with a diameter of $12.7 \mathrm{~mm}$ and an overall mass of $3.2 \mathrm{~kg}$. The drop-weight impact experiments were conducted at three energy levels, i.e. $4.5 \mathrm{~J}, 7.5 \mathrm{~J}$ and $10.5 \mathrm{~J}$, and three replicate CF/PEEK and CF/Epoxy composite specimens were tested at each energy level. The impact energy was varied by adjusting the height of the impactor. For the impact energies of $4.5,7.5$ and $10.5 \mathrm{~J}$, with the $3.2 \mathrm{~kg}$ impactor, then the corresponding impact velocities were $1.68,2.16$ and $2.56 \mathrm{~m} . \mathrm{s}^{-1}$, respectively. A catching system was used to restrain the impactor at the end of the impact test. No software filtering of the output force-signal was employed and the software for the instrumented dropweight test equipment provided the impact load and displacement as a function of the time-scale of the impact event. The displacement was calculated, via the software supplied by CEAST, by double integration of the load versus time response from the load cell in the impactor using Newton's second law. 
All the impacted composite specimens were examined to evaluate the degree of interlaminar delamination, i.e. interlaminar cracking, using a portable ‘Prisma 16:64 TOFD' ultrasonic C-scan device, supplied by Sonatest Ltd., UK [47]. This has a phased-array probe integrated with sixteen pulsars/receivers. The probe also equipped with a $16 \mathrm{~mm}$ encoder, which is used to provide the position of the probe along the scan axis. A water spray was applied as the contact agent on the top surface of the CFRP plate to eliminate the effect of air and ensure the effectiveness of the transmission of the ultrasonic waves. Ultrasonic C-scan imaging is one the most widespread NonDestructive Testing (NDT) techniques for composite damage evaluation. Ultrasonic waves with frequencies ranging between 0.5 to $50 \mathrm{MHz}$ are transmitted through the composite to be tested and, upon encountering a discontinuity or delamination in the composite, the waves are reflected back to the transducer. The position and size of a delamination can be determined by comparing the total travel time, which gives the location of the delamination, and the amplitude of the wave, which gives the size of the delamination, when the transmitted wave is reflected from both a delamination and the back face of the CFRP. The C-scan maps are presented in the form of a colour map providing a detailed depth distribution of the damage area but, of course, the C-scan maps can only represent the superimposed delamination areas present in the various composite plies. The delaminations tend to increase in extent the further one goes from the point of impact, i.e. the smaller delamination areas are present between the upper impacted surface plies whilst the largest delamination areas are between the lowest plies near the back face. Therefore, it is important to scan from the impacted face [47].

\section{The Damage Model}

\subsection{Introduction}

The implementation of the 3-D FEA numerical model for predicting the intralaminar and interlaminar damage suffered by the composite during the impact event is shown schematically in the flowcharts in Fig. 2, for one computational time-step and a single integration point. The flowcharts of both the main model and the EP model, which was incorporated as a user-defined material ('VUMAT') sub-routine into the main FEA code ('Abaqus/Explicit 2018'), are given. The FEA simulation would typically be run from 0 to about $6 \mathrm{~ms}$, with about 100 time-steps being employed, and each computational time-step was performed for every appropriate single integration point. The numerical model runs were stopped when the defined total computation time for the impact simulation event had expired. 


\subsection{The intralaminar damage model}

\subsubsection{Introduction}

The types of intralaminar damage that are typically observed in composite laminates consist of plastic deformation of the matrix, matrix cracking, fibre debonding and localised fibre failure.

\subsubsection{The material response prior to the initiation of intralaminar damage}

In the intralaminar damage modelling studies an extended 3-D EP model $[35,36,48-52]$ has been used to capture the elastic-plastic material response prior to the initiation of matrix cracking, etc, since this enables a more accurate prediction of the impact behaviour of the composite laminate, see Appendix A for full details. The constitutive relation for the EP model can be obtained by combining the classic elastic model with the extended plastic model and is given by:

$$
\left\{\begin{array}{l}
d \varepsilon_{11} \\
d \varepsilon_{22} \\
d \varepsilon_{33} \\
d \gamma_{12} \\
d \gamma_{13} \\
d \gamma_{23}
\end{array}\right\}=\left[\begin{array}{cccccc}
1 / E_{11} & -v_{21} / E_{11} & -v_{31} / E_{11} & 0 & 0 & 0 \\
-v_{12} / E_{22} & 1 / E_{22} & -v_{32} / E_{22} & 0 & 0 & 0 \\
-v_{13} / E_{33} & -v_{23} / E_{33} & 1 / E_{33} & 0 & 0 & 0 \\
0 & 0 & 0 & 1 / G_{12} & 0 & 0 \\
0 & 0 & 0 & 0 & 1 / G_{13} & 0 \\
0 & 0 & 0 & 0 & 0 & 1 / G_{23}
\end{array}\right]\left\{\begin{array}{l}
d \sigma_{11} \\
d \sigma_{22} \\
d \sigma_{33} \\
d \tau_{12} \\
d \tau_{13} \\
d \tau_{23}
\end{array}\right\}+\left\{\begin{array}{l}
d \varepsilon_{11}^{p} \\
d \varepsilon_{22}^{p} \\
d \varepsilon_{33}^{p} \\
d \gamma_{12}^{p} \\
d \gamma_{13}^{p} \\
d \gamma_{23}^{p}
\end{array}\right\}
$$

where $d \varepsilon_{i j}$ and $d \gamma_{i j}(i, j=1,2,3)$ are the incremental total strains and $d \sigma_{i j}$ and $d \tau_{i j}(i, j=1,2,3)$ are the incremental stresses. The parameters $v_{i j}(i, j=1,2,3, i \neq j)$ are the Poisson's ratios, $E_{i i}(i, j=$ $1,2,3, i=j$ ) are the Young's moduli either for tension or compression loading, which are generally considered to be similar for composite laminates [25], and $G_{i j}(i, j=1,2,3, i \neq j)$ are the shear moduli. The parameters $d \varepsilon_{i j}^{p}$ and $d \gamma_{i j}^{p}(i, j=1,2,3)$ represent the incremental plastic strains, which are related to the equivalent stress, $\sigma_{e q u}$, and the equivalent plastic strain, $\varepsilon_{e q u}^{p}$. The equivalent stress, $\sigma_{e q u}$, is given by:

$$
\sigma_{e q u}=\sqrt{\frac{3}{2}\left(\sigma_{22}^{2}+\sigma_{33}^{2}\right)-3 \sigma_{22} \sigma_{33}+3 a_{44} \tau_{23}^{2}+3 a_{55} \tau_{13}^{2}+3 a_{66} \tau_{12}^{2}}
$$

where $a_{44}, a_{55}$ and $a_{66}$ are coefficients which indicate the extent of anisotropy in the plastic behaviour. For transversely isotropic solids which are linearly elastic in the fibre direction, i.e. a unidirectional fibre-reinforced composite, the value of the coefficient $a_{44}$, associated with the term $\tau_{23}^{2}$, can be set as having a value of two and the coefficient $a_{55}$, associated with $\tau_{13}^{2}$, is equal in value to the coefficient $a_{66}$, associated with $\tau_{12}^{2}$. Now, the coefficient $a_{66}$ can be readily determined from off-axis tension and compression stress versus strain experiments conducted at different values of the off-axis angle, 
relative to the fibre direction, using a unidirectional composite [e.g. 35,36,51,52], as described in Appendix A. The relationship between the equivalent stress, $\sigma_{e q u}$, and the equivalent plastic strain, $\varepsilon_{e q u}^{p}$, can be expressed as a power-law function, given by:

$$
\varepsilon_{e q u}^{p}=A \sigma_{e q u}{ }^{n}
$$

where $A$ and $n$ are material constants, which are determined by fitting to the $\sigma_{e q u}$ versus $\varepsilon_{e q u}^{p}$ data, as obtained from the off-axis experiments when different off-axis angles are employed using a unidirectional composite [e.g. 35,36,51,52], again see Appendix A. The determination of the coefficient, $a_{66}$, and the constants, $A$ and $n$, allow the calculation of the incremental plastic strains, $d \varepsilon_{i j}^{p}$ and $d \gamma_{i j}^{p}(i, j=1,2,3)$, as given by:

$$
\left\{\begin{array}{l}
d \varepsilon_{11}^{p} \\
d \varepsilon_{22}^{p} \\
d \varepsilon_{33}^{p} \\
d \gamma_{12}^{p} \\
d \gamma_{13}^{p} \\
d \gamma_{23}^{p}
\end{array}\right\}=\frac{A n}{\sigma_{e q u}{ }^{1-n}}\left\{\begin{array}{c}
0 \\
3\left(\sigma_{22}-\sigma_{33}\right) / 2 \sigma_{\text {equ }} \\
3\left(\sigma_{33}-\sigma_{22}\right) / 2 \sigma_{e q u} \\
3 a_{66} \tau_{12} / 2 \sigma_{\text {equ }} \\
3 a_{55} \tau_{13} / 2 \sigma_{\text {equ }} \\
3 a_{44} \tau_{23} / 2 \sigma_{\text {equ }}
\end{array}\right\} d \sigma_{\text {equ }}
$$

\subsubsection{The initiation of intralaminar damage}

The 3-D damage criteria that were employed to capture the initiation of intralaminar damage such as matrix cracking, etc. were proposed by Daniel et al. [38-40,43-45] and are usually referred to as the Northwestern University (NU) failure criteria. They are partially interactive damage criteria, which means that more than one stress component may be used in them. These damage criteria represent the intralaminar damage that may be induced in a composite ply via: longitudinal tensile stresses, longitudinal compressive stresses, transverse tensile stresses, transverse compressive stresses, transverse shear stresses, through-thickness tensile stresses, through-thickness compressive stresses and through-thickness shear stresses. The mathematical details of the damage initiation model for a composite ply are given in Table 1 , where $\sigma_{i j}$ and $\tau_{i j}$ are the normal and shear stresses and $F_{i T}(i=1,2,3), F_{i C}(i=1,2,3)$ and $F_{i S}(i=2,3)$ are the tensile, compressive and shear damage criteria in the three material directions, respectively, and the initiation of damage is predicted to occur when $F \geq 1$. The terms $S_{i t}(i=1,2,3)$ are the tensile strengths in the three material directions and $S_{i c}(i=1,2,3)$ are the compressive strengths in the three material directions. Finally, $S_{12}, S_{13}$ and $S_{23}$ represent the shear strengths in the corresponding material directions. The definition of the combined stresses at the onset of the initiation of the intralaminar damage and final failure, $\sigma^{0}$ and $\sigma^{f}$, respectively, are given in Table 2 . 


\subsubsection{The propagation of intralaminar damage}

Corresponding to the damage initiation mechanisms defined in the damage criteria [38-40], eight damage variables, $d_{1 t}, d_{1 c}, d_{2 t}, d_{2 c}, d_{2 s}, d_{3 t}, d_{3 c}$ and $d_{3 s}$, may be defined to indicate the propagation of intralaminar damage in a composite ply. A general form of the damage variable, $d$, for all types of damage initiation, is given by [25]:

$$
d=\frac{\left(\varepsilon^{f}-\varepsilon_{p}\right)\left(\varepsilon-\varepsilon^{0}\right)}{\left(\varepsilon-\varepsilon_{p}\right)\left(\varepsilon^{f}-\varepsilon^{0}\right)}
$$

where the strain, $\varepsilon$, is the combined strain in the composite ply and the strain values $\varepsilon^{0}$ and $\varepsilon^{f}$ are the combined strains corresponding to the initiation of damage and final failure, respectively. The term $\varepsilon_{p}$ is the combined plastic strain. The equations for the damage variable for a particular type of damage, and the corresponding combined strains, are given in Table 3, noting that $\gamma_{i j}=2 \varepsilon_{i j}$. The final failure strain, $\varepsilon_{i j}^{f}(i, j=1,2,3)$, can be determined by $[53,54]$ :

$$
\varepsilon_{i j}^{f}=\left.2 G_{c}\right|_{i j} /\left(\sigma_{i j}^{0} l_{c}\right)
$$

where the respective values of $\left.G_{c}\right|_{i j}$ are the tensile, $\left.G_{I c}\right|_{f t}$, and compressive, $\left.G_{I c}\right|_{f c}$, intralaminar ply fracture energies in the longitudinal fibre-direction and the tensile, $\left.G_{I c}\right|_{m t}$, compressive, $\left.G_{I c}\right|_{m c}$, and shear, $\left.G_{I I c}\right|_{m s}$, intralaminar ply fracture energies in the transverse directions. The term $\sigma_{i j}^{0}$ is the stress corresponding to damage initiation and $l_{c}$ is the characteristic length which can be determined based on the volume of the elements $[53,54]$. During the evolution of intralaminar damage, the elasticity matrix needs to be degraded to compute the values of the degraded stresses. To achieve this, four damage parameters, $d_{1}, d_{2}, d_{3}$ and $d_{s}$, which reflect the longitudinal damage, transverse damage and through-thickness damage and shear damage, respectively, were derived from the eight damage variables, $d_{1 t}, d_{1 c}, d_{2 t}, d_{2 c}, d_{2 s}, d_{3 t}, d_{3 c}$ and $d_{3 s}$, corresponding to the types of damage previously discussed, as follows [25]:

$$
\begin{array}{ll}
\text { Longitudinal damage: } & d_{1}= \begin{cases}d_{1 t}, & \text { and } \sigma_{11} \geq 0 \\
d_{1 c}, & \text { and } \sigma_{11}<0\end{cases} \\
\text { Transverse damage: } & d_{2}= \begin{cases}d_{2 t}, & \left|\sigma_{22}\right| \geq\left|\tau_{12}\left(\tau_{23}\right)\right| \text { and } \sigma_{22} \geq 0 \\
d_{2 c}, & \left|\sigma_{22}\right| \geq\left|\tau_{12}\left(\tau_{23}\right)\right| \text { and } \sigma_{22}<0 \\
d_{2 s}, & \left|\sigma_{22}\right|<\left|\tau_{12}\left(\tau_{23}\right)\right|\end{cases} \\
\text { Through-thickness damage: } & d_{3}= \begin{cases}d_{3 t}, & \left|\sigma_{33}\right| \geq\left|\tau_{13}\left(\tau_{23}\right)\right| \text { and } \sigma_{33} \geq 0 \\
d_{3 c}, & \left|\sigma_{33}\right| \geq\left|\tau_{13}\left(\tau_{23}\right)\right| \text { and } \sigma_{33}<0 \\
d_{3 s}, & \left|\sigma_{33}\right|<\left|\tau_{13}\left(\tau_{23}\right)\right|\end{cases} \\
\text { Shear damage: } & d_{s}=1-\left(1-d_{1}\right)\left(1-d_{2}\right)\left(1-d_{3}\right)
\end{array}
$$


The damage parameters, $d_{1}, d_{2}, d_{3}$ and $d_{s}$, have the value of 0 when the element is undamaged and 1 when fully damaged and they were used to degrade the elasticity matrix to form the damaged elasticity matrix, $C_{d}$, given by [25]:

$C_{d}=\frac{1}{D}\left[\begin{array}{cccccc}\left(1-d_{1}\right) E_{11} & \left(1-d_{1}\right)\left(1-d_{2}\right) v_{21} E_{11} & \left(1-d_{1}\right)\left(1-d_{3}\right) v_{31} E_{11} & 0 & 0 & 0 \\ \left(1-d_{1}\right)\left(1-d_{2}\right) v_{12} E_{22} & \left(1-d_{2}\right) E_{22} & \left(1-d_{2}\right)\left(1-d_{3}\right) v_{32} E_{22} & 0 & 0 & 0 \\ \left(1-d_{1}\right)\left(1-d_{3}\right) v_{13} E_{33} & \left(1-d_{2}\right)\left(1-d_{3}\right) v_{23} E_{33} & \left(1-d_{3}\right) E_{33} & 0 & 0 & 0 \\ 0 & 0 & 0 & \left(1-d_{s}\right) G_{12} D & 0 & 0 \\ 0 & 0 & 0 & 0 & \left(1-d_{s}\right) G_{13} D & 0 \\ 0 & 0 & 0 & 0 & 0 & \left(1-d_{s}\right) G_{23} D\end{array}\right]$

where the term $D$ is given by [25]:

$$
\begin{aligned}
& D=1-\left(1-d_{1}\right)\left(1-d_{2}\right) v_{12} v_{21}-\left(1-d_{2}\right)\left(1-d_{3}\right) v_{23} v_{32}-\left(1-d_{3}\right)\left(1-d_{1}\right) v_{31} v_{13} \\
& -2\left(1-d_{1}\right)\left(1-d_{2}\right)\left(1-d_{3}\right) v_{12} v_{23} v_{31}
\end{aligned}
$$

and the degraded stresses were then calculated from [25]:

$$
\sigma_{i j}=C_{d} \varepsilon_{i j}^{e}
$$

in which $\sigma_{i j}$ is the resulting stress and $\varepsilon_{i j}{ }^{e}$ is the current elastic strain. It should be noted that intralaminar matrix cracks, as such, are not physically present in this 'smeared-crack' model but only their effects on the stiffness of the ply elements, via Eqs. (7) to (13). These degraded stresses and updated strains were then read as being the new material state, for a given element, in the next step of the run of the FEA model. In the intralaminar damage model, the criterion used for the deletion of elements was based on the determinant of the damage parameters, $d_{1}, d_{2}, d_{3}$ and $d_{s}$. If any of these damage parameters met the criterion $d_{\mathrm{i}}(i=1,2,3, s) \geq 0.99$, the corresponding elements were deleted. For the simulations of the extent of intralaminar damage as a function of the time-scale of the impact event that are deduced from the model then, following earlier work $[7,22,53]$, a value for the particular damage parameter of equal to, or greater, than 0.9 was used to define the relatively intense intralaminar damage, i.e. to calculate the predicted areas of intralaminar damage in the figures shown later.

\subsection{The interlaminar damage model}

\subsubsection{Introduction}

Interlaminar damage typically involves the initiation and growth of delaminations, i.e. interlaminar cracking, between the plies that make up the composite laminate and this was captured using the 'Abaqus/Explicit' built-in surface-based cohesive (i.e. interface) element, having a zero thickness, using a fracture-mechanics approach [25]. Basically, the interface element was described via a cohesive (i.e. damage) surface law [28-30] where the traction, $t$, is a function of the displacement, $\delta$, as shown schematically in Fig. 3 , and is in the form of a bilinear cohesive law for a 
linear-softening material model. This cohesive surface law was implemented in the FEA code [25] via an interface element. In the present work, as noted above, a 3-D approach has been taken, see Fig. 3 , and the traction vector, $t$, consists of three components which represent $t_{33}$ the normal traction and the two shear tractions $t_{31}$ and $t_{32}$, respectively. The equation, $k=\alpha E_{33} / t_{p}$, as reported in [30], was employed to determine the initial cohesive stiffness, $k_{i}(i=33,31,32)$; where $\alpha$ is a constant much larger than unity, i.e. $\alpha \gg 1, E_{33}$ is the transverse Young's modulus of the composite and $t_{p}$ is the thickness of two adjacent three block layers (i.e. $0.750 \mathrm{~mm}$ ). The values of the cohesive stiffness along the normal, $k_{33}$, the first shear, $k_{31}$, and the second shear, $k_{32}$, directions were assumed to be equal. The embedded interface element requires a value of the interlaminar fracture energy, $G_{c}$, to be inputted and this represents the area under the bilinear cohesive law, see Fig. 3 . This damage law is divided into two steps. Before the initiation of any delamination, the relationship possesses linearelastic behaviour with a stiffness of $k$. Once the interlaminar damage criterion is satisfied, at a value of the displacement of $\delta^{o}$, the cohesive stiffness degrades linearly until separation of the interface occurs when the traction, $t$, tends to zero. Thus, the interlaminar delamination propagates, i.e. interlaminar cracking results, when the maximum failure displacement of $\delta^{f}$ is attained. Finally, the initiation and growth of any intralaminar damage, as discussed above, significantly influences the extent of interlaminar damage and hence these two damage modes were modelled to be interactive in the 'Abaqus/Explicit' simulation, see Fig. 2.

\subsubsection{Initiation of interlaminar damage}

In the interlaminar damage model an elastic constitutive relation was employed to capture the response prior to delamination initiation and a quadratic-stress criterion was employed to govern damage initiation at a composite ply interface $[25,26]$ which states that delamination initiation occurs when:

$$
\left(\frac{\left\langle t_{33}\right\rangle}{t_{33}^{0}}\right)^{2}+\left(\frac{t_{31}}{t_{31}^{0}}\right)^{2}+\left(\frac{t_{32}}{t_{32}^{0}}\right)^{2}=1
$$

where the term $t_{i}(i=33,31,32)$ represents the current normal or shear stresses and $t_{i}^{0}(i=33,31,32)$ represents the normal and shear cohesive strengths. The corresponding displacements are denoted by $\delta_{33}, \delta_{31}$ and $\delta_{32}$, and by $\delta_{33}^{0}, \delta_{31}^{0}$ and $\delta_{32}^{0}$, respectively. The value of the cohesive strength, $t_{33}^{0}$, was determined from the theory proposed in $[30,55]$, which maintains computation accuracy whilst avoiding a very fine mesh and a commensurate increase in computational cost, and for the shear cohesive strengths then $t_{31}^{0}=t_{32}^{0}$. Thus, Eq. (14), for a 3-D 
model, leads to the onset of damage initiation at $\delta^{0}$, see Fig. 3 , being defined at a value of the combined displacement in the cohesive law when:

$$
\sqrt{\left\langle\delta_{33}{ }^{2}\right\rangle+\delta_{31}{ }^{2}+\delta_{32}{ }^{2}}=\sqrt{\left\langle\delta_{33}^{0}{ }^{2}\right\rangle+\delta_{31}^{0}{ }^{2}+\delta_{32}^{0}}
$$

as discussed in more detail below.

\subsubsection{Evolution of interlaminar damage}

The energy-based Benzeggagh-Kenane (B-K) $[31,32]$ criterion for Mixed-mode propagation was used to derive a total value $G_{c}$ for the growth of the delamination between the composite plies and is given by $[55,56]$ :

$$
G_{c}=G_{I C}+\left(G_{I I C}-G_{I C}\right)\left(\frac{G_{I I}+G_{I I I}}{G_{I}+G_{I I}+G_{I I I}}\right)^{\eta}
$$

where $G_{I C}$ is the Mode I (opening tensile), $G_{I I C}$ is the Mode II (in-plane shear) interlaminar facture energy, and $\eta$ is the B-K Mixed-mode interaction exponent. The values of $G_{I C}, G_{I I C}$ and $\eta$ may all be experimentally measured $[31,32,56,57]$ and so inputted into the FEA model. The parameters $G_{I}, G_{I I}$ and $G_{I I I}$ are the current Mode I, Mode II and Mode III (anti-plane shear) energy-release rates, respectively, as calculated from the FEA code. For the node at the interlaminar crack tip, an interlaminar damage parameter, $d_{\text {inter }}$, may be defined from degrading the initial cohesive stiffness, $k_{i}(i=33,31,32)$, i.e. as the interlaminar damage after initiation now evolves to the point when separation occurs, see Fig. 3 . This interlaminar damage parameter, $d_{i n t e r}$, starts with a value of 0 when $\delta=\delta^{o}$ and finishes with a value of 1 when $\delta=\delta^{f}$ according to the relationship [25,32]:

$$
d_{\text {inter }}=\frac{\delta^{f}\left(\delta-\delta^{0}\right)}{\delta\left(\delta^{f}-\delta^{0}\right)}
$$

where the term $\delta$ is the combined displacement, $\sqrt{\left\langle\delta_{33}{ }^{2}\right\rangle+\delta_{31}{ }^{2}+\delta_{32}{ }^{2}}$, at a delamination interface. In the schematic in Fig. 3, the onset of damage initiation at $\delta^{0}$ occurs according to Eq. (15) above, i.e. when $\sqrt{\left\langle\delta_{33}{ }^{2}\right\rangle+{\delta_{31}}^{2}+\delta_{32}{ }^{2}}=\sqrt{\left\langle\delta_{33}^{0}{ }^{2}\right\rangle+\delta_{31}^{0}{ }^{2}+{\delta_{32}^{0}}^{2}}$, and failure of the interface element, i.e. interlaminar delamination, i.e. cracking, occurs, at $\delta^{f}$ when [25,32]:

$$
\sqrt{\left\langle\delta_{33}{ }^{2}\right\rangle+\delta_{31}{ }^{2}+\delta_{32}{ }^{2}}=\sqrt{\left\langle\delta_{33}^{f^{2}}\right\rangle+{\delta_{31}^{f}}^{2}+\delta_{32}^{f^{2}}}
$$

It should be noted that implementing the concept of the interlaminar damage parameter, $d_{\text {inter }}$, (a) ensures that the irreversibility of the damage is taken into account and (b) enables the 
cohesive tractions, after the damage initiation point has been attained, to be calculated via the expression [25]:

$$
\left\{\begin{array}{l}
t_{33} \\
t_{31} \\
t_{32}
\end{array}\right\}=\left[\begin{array}{ccc}
\left(1-d_{\text {inter }}\right) k_{33} & 0 & 0 \\
0 & \left(1-d_{\text {inter }}\right) k_{31} & 0 \\
0 & 0 & \left(1-d_{\text {inter }}\right) k_{32}
\end{array}\right]\left\{\begin{array}{c}
\delta_{33} \\
\delta_{31} \\
\delta_{32}
\end{array}\right\}
$$

The importance of calculating the cohesive stress is that the interlaminar damage process takes place over many time steps when the model is running and the displacement, $\delta$, for the node at the delamination crack-tip steadily increases. After the damage initiation point of has been attained in the cohesive law, there is a subsequent increase of $d_{\text {inter }}$ and this leads to the steady reduction of the cohesive stress to zero for the node at the crack tip, at which point the node is released and the interlaminar crack, i.e. delamination, advances to the next node. As a result, the stresses and strains in elements surrounding the nodes will also be affected and, hence, nearby elements may now be subjected to intralaminar damage, as described above. Of course, there may be more than one interlaminar crack tip present and as a result several crack-tip nodes may be subjected to their own traction versus displacement relationship, as determined above. The cohesive law properties were read into the cohesive surface model, for a given interface element, in each step of the FEA model, see Fig. 2. For the simulations of the details of the interlaminar cracking, i.e. delamination, that are deduced from the FEA model then, following earlier work $[7,22,53]$, a value of the damage parameter, $d_{\text {inter }}$, equal to, or greater, than 0.9 is used, i.e. to calculate the predicted areas of delamination in the figures shown later.

\section{The Finite Element Analysis (FEA) Model}

The FEA numerical model was created in 'Abaqus/Explicit 2018' [25] to simulate the impact behaviour of the composite test specimens. The implementation of the 3-D EP FEA numerical simulation is shown schematically in the flowcharts in Fig. 2, for one computational time-step and a and a single integration point. The flowcharts of both the main model and the EP damage model, which was implemented as a 'VUMAT' sub-routine and runs simultaneously alongside the main model in the FEA simulation, are given in Fig. 2. In the FEA simulation model, each composite ply was modelled as a three-dimensional deformable part and meshed using eight-noded linear-reduced integration (C3D8R) solid-elements with a size of $1.5 \mathrm{~mm} \times 1.5 \mathrm{~mm}$, at this element size the FEA model gave mesh-independent results. Cohesive surfaces were defined, between composite plies with different fibre directions, to capture the delamination $[20,58]$ in the CFRP specimens. The hemispherical steel impactor was modelled as an analytical rigid surface and only assigned one 
degree of freedom, which aligned with the through-thickness direction of the composite specimens. The general contact algorithm was invoked to govern the global interaction between the impactor and the composite specimen [54,59]. Friction coefficients of 0.2 and 0.25 were defined in the global contact and cohesive contact, respectively $[60,61]$. The computation accuracy was set as 'double precession' to reduce the accumulation of errors when running the simulation. The total number of elements in the finite element model for the composite specimen was 53,600. The FEA simulation would typically be run from 0 to about $6 \mathrm{~ms}$, with about 100 time-steps being employed, and each computational time-step was performed for a single integration point. The numerical model run was stopped when the defined total computation time for the impact simulation event had expired. Computations were completed using 16 CPUs on a Linux Cluster with a run time of 10 to $16 \mathrm{~h}$, depending on the properties of the composite laminates. The material input parameters for the CF/PEEK and CF/Epoxy composites required for the FEA numerical models are presented in Table 4 $[21,48,52,53,62]$. These properties were typically measured at strain-rates in the range of $10^{-3}$ to $10^{0}$ $\mathrm{s}^{-1}$. The strain-rate for the composite test specimens for the low-velocity drop-weight tests is about $3 \mathrm{~s}$

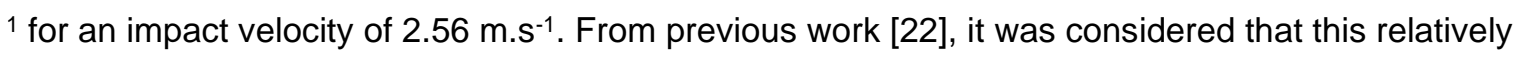
low value of strain-rate would not lead to significantly different values of the material properties to those shown in Table 4 and these properties were therefore used in the FEA modelling studies for the low-velocity impact tests.

\section{Results and Discussions}

\subsection{Loading response}

Figs. 4 and 5 show a comparison between the load versus time curves and the load versus (out-of-plane) displacement curves, respectively, obtained from the impact experiments and the 3-D EP FEA simulations for the CF/PEEK and CF/Epoxy composite specimens, respectively. As may be seen, for both the CF/PEEK and CF/Epoxy composites, the overall load response, i.e. the maximum loads, impact duration times and maximum out-of-plane displacements, are accurately captured by the predictions from the 3-D EP FEA model for all three impact energy levels. The relatively small amplitude, sinusoidal oscillations on the initially-rising part of the load versus time experimental curves seen for all the impact energies are indicative of mass-spring oscillations, as first analysed in detail in [63-67]. These mass-spring oscillations, especially their frequency, are also captured well by the predictions from the 3-D EP FEA modelling studies. 
In Figs. 4c and 5c, for the CF/PEEK composite struck with an impact energy (IE) of $7.5 \mathrm{~J}$, it can be seen that the experimental loading responses exhibit an appreciable decrease in the load, and an increase in the associated subsequent oscillations, at a load just somewhat higher than $3 \mathrm{kN}$. (It should be noted that these features are more evident when these figures are magnified in scale.) This significant load drop is indicative of the initiation of damage in the composite specimen. These oscillations that occur after the first point of significant load drop, which is often called the incipient force, $P_{i}$, are associated with the first failure of the CFRP that occurs, e.g. matrix cracking, and subsequent damage propagation, but does not exclude formation of cracks and delamination at an earlier stage, as has been described in detail by Bienias et al. [67].

Similarly, for the CF/PEEK composite at an IE $=10.5 \mathrm{~J}$, see Figs. $4 \mathrm{e}$ and $5 \mathrm{e}$, the experimental loading responses also show an appreciable decrease in the load, and an increase in the associated subsequent oscillations, at approximately just greater than $3 \mathrm{kN}$, which is again indicative of damage initiation. For both an $\mathrm{IE}=7.5 \mathrm{~J}$ and an $\mathrm{IE}=10.5 \mathrm{~J}$, the 3-D EP FEA model accurately predicts this onset of damage. Furthermore, the presence of delaminations at these impact energies is experimentally and theoretically confirmed by the C-scan results, as discussed below. However, for the CF/PEEK composite at an IE=4.5 J, see Figs. $4 \mathrm{a}$ and $5 \mathrm{a}$, all three replicate experiments show no significant decreases in the load, near the maximum load. This indicates that no damage occurs in the CF/PEEK at an IE=4.5 J. It should be noted that the maximum load for the CF/PEEK at an IE=4.5 J is approximately $3 \mathrm{kN}$, and this maximum load therefore appears to be just below the threshold load for damage to initiate, as is confirmed by the lack of delaminations detected from the experimental Cscan results which are discussed below.

Figs. 4 and 5 also show the results for the CF/Epoxy composite specimens which reveal significant decreases in the measured loads at about 2.6 to $2.8 \mathrm{kN}$, and an increase in the associated subsequent oscillations, indicative of the initiation of damage occurring at all the impact energies used. Thus, the impact energies of 4.5, 7.5 and $10.5 \mathrm{~J}$ are all sufficient to produce a loading in excess of the threshold load for damage initiation in the CF/Epoxy composite specimens. The results from the 3-D EP FEA model predict these significant load drops, and an increase in the associated subsequent oscillations, in agreement with the experimental measurements. Indeed, the presence of delaminations at all these impact energies is experimentally and theoretically confirmed by the C-scan results, as discussed below. 


\subsection{Energy dissipation}

Fig. 6 shows the average energy dissipation, i.e. the initial kinetic energy minus the final kinetic energy of the impactor, versus the impact energy for the CF/PEEK and CF/Epoxy composite specimens at impact energy levels of $4.5,7.5$ and $10.5 \mathrm{~J}$. As may be seen, the energy dissipation increases monotonically with the impact energy and the results predicted using the 3-D EP FEA model are in very good agreement with the experimental results. Indeed, the differences between the predicted and experimentally-measured energy dissipations for the CF/PEEK and CF/Epoxy composite specimens are within about \pm 2 to $\pm 10 \%$ at all the impact energy levels investigated. It is of interest to note, as discussed in detail below, that as the energy dissipation increases then the extent of interlaminar delaminations, as measured from the C-scan tests and as predicted from the numerical simulation studies, also increase.

\subsection{Impact-induced damage}

Fig. 7 presents the cross-sectional views of the predicted intralaminar matrix damage obtained from the simulation of an impact on the CF/PEEK and CF/Epoxy composite specimens at energy levels of $4.5,7.5$ and $10.5 \mathrm{~J}$. The predicted intralaminar damage is shown as the red-coloured areas in these schematic cross-sectional views. It can be seen that, at the same energy level, the CF/Epoxy composites exhibit more extensive intralaminar matrix damage than the CF/PEEK composites. Indeed, the extent of intralaminar damage for the CF/PEEK composite at an IE=4.5 $\mathrm{J}$ is predicted to be very limited. It should be noted that, with an increasing impact energy, more intralaminar damage can be seen in the cross-sectional views of both the CF/PEEK and the CF/Epoxy composites and that the intralaminar damage is predicted to be most extensive near the rear (non-impacted) face of the specimen, as indeed would be expected since the strains are tensile and are highest in this region.

A comparison between the experimentally-measured and the predicted footprint areas of the interlaminar damage, i.e. interlaminar cracking, obtained for the CF/PEEK composite specimens impacted at 4.5, 7.5 and $10.5 \mathrm{~J}$ is shown in Fig. 8. The right-hand side scale in Fig. 8, and similar figures, indicates the location of the measured interlaminar delaminations as a function of the depth through the thickness of the specimen, where the dark red colour represents the front (impacted) face and the dark blue colour represents the rear (non-impacted) face of the composite specimen. The $0^{\circ}$ fibre direction is also indicated. The areal footprint of the damage detected from the experimental Cscan tests is given at the top for each specimen and was determined by counting the number of pixels 
which had a colour which was not dark blue, as the rear surface simply reflects the ultrasound and appears as being dark blue in colour. A white-dashed line has been drawn around the overall area for the experimentally-measured delamination footprint, which encompasses the total area of the footprint as measured from the C-scan tests. The red solid line is the predicted area of the interlaminar delamination footprint from the 3-D EP FEA modelling studies. In Fig. 8, for the CF/PEEK composites for an IE of 7.5 and $10.5 \mathrm{~J}$, the agreement between the experimentally-measured and predicted delamination areas is very good. However, for an IE of $4.5 \mathrm{~J}$, no delaminations were detected using the C-scan tests but the numerical model predicts slight delamination damage. In this respect, it should be recalled that the measured loading responses in Fig. 4a and Fig. $5 \mathrm{a}$ for an IE of $4.5 \mathrm{~J}$ also exhibited no evidence of a load drop as the maximum load was approached. However, the modelling studies did exhibit a slight load drop near the maximum load, which is consistent with the prediction of a small extent of delamination at an IE $=4.5 \mathrm{~J}$. Thus, from the modelling studies, an impact at IE $=4.5 \mathrm{~J}$ is just sufficient to produce a small area of delamination but this is not observed in the actual impact experiments. An interpretation of this is that, in the modelling studies, the stress predicted to initiate delaminations at an IE of $4.5 \mathrm{~J}$ is lower than that actually required in the impact experiments. Hence, interlaminar delamination is predicted when none is actually observed experimentally at an $\mathrm{IE}=4.5 \mathrm{~J}$. As pointed out earlier, this is likely to be a consequence of the maximum load for an IE of $4.5 \mathrm{~J}$ for the CF/PEEK composite being near the threshold load for damage initiation, i.e. just over $3 \mathrm{kN}$. On the other hand, for an IE of 7.5 and $10.5 \mathrm{~J}$ for the CF/PEEK composite, the maximum load is significantly above the threshold load required for damage initiation and delaminations are therefore correctly predicted to occur. Indeed, the predicted areas of the delaminations increase in extent as the impact energy is increased from 7.5 to $10.5 \mathrm{~J}$, in excellent agreement with the experimentally-measured values.

A comparison between the experimentally-measured and the predicted footprint area of the interlaminar damage, i.e. interlaminar cracking, obtained for the CF/Epoxy composite specimens impacted at 4.5, 7.5 and $10.5 \mathrm{~J}$ is shown in Fig. 9. This comparison between the areas of the delamination footprints demonstrates a very good agreement between the experiments and simulations at all the various impact energies that were employed. Indeed, both the predicted and the experimentally-measured areas of the delamination footprints increase steadily with the impact energy, in agreement with the increasing energy dissipation as shown in Fig. $6 \mathrm{~b}$. 
To further confirm the predictive capability of the 3-D EP FEA model, the extents of the interlaminar delaminations from the experimental and modelling studies obtained at an impact energy level of $10.5 \mathrm{~J}$ are compared in detail in Figs. 10 and 11. Now, the use of the present 3-D EP model enables exploded maps of this interlaminar cracking to be predicted, see Figs. 10b and 11b. In Fig. 10a a comparison between the experimental and predicted footprint areas of the interlaminar delaminations obtained from the CF/PEEK composite specimen struck with an impact energy of 10.5 $\mathrm{J}$ is shown. The exploded view of these predicted delaminations in the CF/PEEK composite specimen, impacted at $10.5 \mathrm{~J}$ energy level, is shown in Fig. 10b. Likewise, the experimental and predicted footprint areas of this interlaminar cracking exhibited by the CF/Epoxy composite specimen, struck with an impact energy of $10.5 \mathrm{~J}$, are shown in Fig. 11a and the exploded view of the predicted delaminations is shown in Fig. 11b. Several interesting observations arise from these results. Firstly, from Figs. 10a and 11a, the agreement between the extents of the measured and predicted areas of the delaminations is clearly very good. Further, it may be recalled that from Figs. 8 and 9 there is a very good quantitative agreement between the measured areas of the delamination footprints from the experimental C-scan results and the predictions from the 3-D EP FEA model. Secondly, considering the areas of the interlaminar delaminations shown in the exploded views in Figs. 10b and $11 \mathrm{~b}$, the extent of the delaminations is predicted to increase towards the rear face of the specimen, in agreement with the experimental C-scan results shown in Figs. 10a and 11a, respectively. Thirdly, the model is able to predict accurately the location and the direction of propagation of the delaminations in the CF/PEEK and in the CF/Epoxy composite specimens. As expected, such interlaminar cracking is predicted to occur preferentially between the adjacent $0^{\circ}$ and $90^{\circ}$ ply directions in the $\left[0_{3} / 90_{3}\right]_{2 \mathrm{~s}}$ cross-ply lay-up, since at these interfaces the values of stiffness, in any one direction, of the adjacent ply layers change dramatically from one ply to the next. Thus, the interfacial stresses thereby generated tend to initiate and propagate delaminations. Fourthly, the shape and orientation of the delaminations are predicted very well by the 3-D EP model simulation, as may be seen from comparing Figs. 10a and 10b, and Figs. 11a and 11b, respectively. For example, as may be seen from the experimental C-scans and as predicted from the modelling studies, the interlaminar delamination that is furthest from the impact face, and is slightly lighter blue in colour than the background, occurs at a depth of between 2.0 to $2.5 \mathrm{~mm}$. This delamination is aligned along the longer dimension of the rectangular specimen, consistent with the direction of the $0^{\circ}$ outer-ply layer, i.e. the orientation of the ply beneath the delamination on the rear surface. Thus, a very good 
correlation is obtained between the details of the experimental and predicted interlaminar delaminations for both the CF/PEEK and the CF/Epoxy composites.

Fig. 12 shows the interactions of the intralaminar damage, i.e. matrix cracking, (coloured orange) and the interlaminar cracking, i.e. delaminations, (coloured red) at about the maximum load at an impact event time of 3 ms for the CF/PEEK composite tested at an impact energy of $10.5 \mathrm{~J}$. (As explained earlier, the intralaminar damage predictions are for when the damage parameter $d_{2}$, corresponding to transverse matrix damage, or the damage parameter $d_{3}$, corresponding to throughthickness matrix damage, are greater than 0.9 , as this value for these damage parameters $d_{2}$ and $d_{3}$ is taken to correspond to matrix cracking damage. Also, of course, it should be noted that intralaminar matrix cracks are not shown in fine detail in the typical 'smeared-crack' FEA numerical model that has been developed but the regions where they would be present are modelled.) There are clearly interactions between the regions of matrix cracking and delamination, in the same way as observed by Topac et al. [68]. This is where tensile and shear stresses in the matrix are highest on either side of the impactor and interlaminar cracking develops between the plies associated with the regions of matrix cracking, and then extends even further away from the impact site. This produces 'tree-like' patterns as experimentally observed in detail by Talreja and Phan [69] which clearly reveal the characteristic conical fracture pattern corresponding to lines of matrix damage spreading away from the impact site, accompanied by extensive delaminations.

An interesting observation is that, for the most part, the predicted delamination footprint is approximately symmetric with the delaminations having a characteristic butterfly shape aligned along the fibre direction (of the lower ply), as is evident in Figs. 10 and 11. However, it is apparent that the predicted intralaminar damage and delamination footprint can be slightly asymmetric, for example see Figs. 7 to 9 and 12, with somewhat more damage on one side of the impact site than the other. This has also been observed in the FEA damage modelling studies reported by other leading researchers [e.g. $1,7,8,10,13,19]$. It should be noted that the damage processes in the FEA models are irreversible. Therefore, when damage does occur in a particular region it absorbs strain energy from around that region which can suppress damage development in neighbouring regions. As a result, it is not unusual for the damage processes predicted from a numerical FEA model to exhibit some asymmetry due to small imperfections in the numerical discretisation and convergence processes, e.g. slight imperfections in meshing and rounding errors [70]. However, the asymmetry effects are 
small and also apparent, of course, in the experimental evaluations and for this reason the predicted damage takes on a more realistic appearance.

\subsection{Comparison of 3-D EP and 3-D Elastic models}

An interesting point is how much does the plasticity introduced into the 3-D EP FEA model play a role in determining the load response and the area of the delamination footprint. To explore this point, Figs. 13 and 14 show the prediction for the 3-D EP model for CF/PEEK compared with a prediction for the 3-D EP model with no plasticity, i.e. a 3-D Elastic only model. These simulations were undertaken for the CF/PEEK composite at an impact energy of $10.5 \mathrm{~J}$, where any effects of plasticity in the composite material would be most marked. Several interesting results may be observed. Firstly, in general, the results from the loading response, see Fig. 13, and delamination footprint, see Fig. 14, for the 3-D EP model, i.e. with plasticity included, are closer in value to the experimental data for CF/PEEK, see Figs. 4e, 5e and 8. Secondly, the 3-D Elastic only model gives a slightly lower maximum load and longer impact duration time which are not so consistent with the experimental data as for the 3-D EP model, see Fig. 4e. Likewise, the maximum displacement for the 3-D Elastic only model is somewhat over predicted, see Fig. 5e. Thirdly, the area of the interlaminar damage footprint for the 3-D EP model is significantly closer in value to the experimental C-scan results, as shown in Fig. 8. Finally, a good feature of the 3-D EP model is that it is firmly based on physical processes, i.e. plastic yielding as experimentally determined from off-axis tension and compression stress versus strain experiments undertaken on the composite material. As explained above and in Appendix A, the coefficient $a_{66}$ is determined from different values of the off-axis angle using a unidirectional composite and the relationship between the equivalent stress, $\sigma_{\text {equ }}$, and the equivalent plastic strain, $\varepsilon_{\text {equ }}^{p}$, is a power-law function, where $A$ and $n$ are the non-linear coefficients $[35,36,51,52]$. In contrast, other researchers have applied a non-linear shear approach, with the nonlinear parameters derived from $V$-notched rail shear tests. However, it is considered that the present approach based on off-axis tension and compression stress versus strain experiments, using the Sun et al. $[35,36]$ anisotropic plasticity model in the 'VUMAT' is more appropriate in some circumstances and will be especially valuable in our future work on modelling adhesively-bonded CFRP repairs.

A point of particular interest is the ability of the 3-D EP model to predict the permanent indentation after the impact event that arises from the impactor striking the CFRP. This indentation was only evident from the experiments from the highest impact energy of $10.5 \mathrm{~J}$ for the CF/PEEK composite specimens. The permanent indentation had a depth of $0.20 \pm 0.02 \mathrm{~mm}$, as measured with 
a profilometer, and a photograph of the impacted surface is shown in Fig. 15a with an enlarged view of the indentation also shown. The permanent indentation deformation of the impacted surface was modelled for the CF/PEEK composite at $10.5 \mathrm{~J}$ and the simulation is shown in Fig. 15b for the 3-D EP model and in Fig. 15c for the 3-D Elastic only model. It should be noted that even for the 3-D Elastic only model, see Fig. 15c, there is a slight indentation due to intralaminar and interlaminar damage but the indentation is clearly more extensive using the 3-D EP FEA model, see Fig. 15b. A side-view of the predicted damage is shown in Fig. 16a for the 3-D EP model and in Fig. 16b for the 3-D Elastic model. It is clearly evident from Figs. 15 and 16 that only the 3-D EP model captures accurately the localisation and degree of the permanent indentation and gives a value for the indentation of between 0.2 to $0.3 \mathrm{~mm}$, which is in very good agreement with the experimentally measured value.

\subsection{Predictions for lower/higher impact energy and reduced specimen thickness}

Now, the 3-D EP FEA model may be used to predict the impact behaviour of the CFRP composite plates outside of the range of impact energies that have been experimentally investigated in the present paper to validate further the model. For example, Figs. 17 and 18 show the load response and delamination footprints, respectively, for impact energies of $1.5 \mathrm{~J}, 10.5 \mathrm{~J}$ and $30 \mathrm{~J}$ on the CF/PEEK composite. It should be noted, of course, that no tests were conducted at the impact energies of 1.5 or $30 \mathrm{~J}$. At an impact energy of $1.5 \mathrm{~J}$, no damage is observed and the load versus time trace is indeed approximately parabolic. On the other hand, at an impact energy of $30 \mathrm{~J}$, the load response clearly indicates appreciable damage has occurred and, from Fig. 18, there is more than twice the interlaminar damage predicted at the impact energy of $10.5 \mathrm{~J}$. These trends are, of course, as would indeed be expected.

Another point of interest is the effect of reducing the thickness of the CFRP composite specimen. Therefore, Figs. 19 and 20 show the predicted load response and delamination footprints, respectively, for CF/PEEK composite specimens modelled using an impact energy of $10.5 \mathrm{~J}$ but with a lay-up of $\left[0_{2} / 9_{2}\right]_{2 s}$, which gives a nominal thickness of $2.0 \mathrm{~mm}$. These predicted results for a $2 \mathrm{~mm}$ thick CF/PEEK composite specimen are compared with the lay-up of $\left[0_{3} / 90_{3}\right]_{2 s}$, as used previously, which resulted in a nominal thickness of $3.0 \mathrm{~mm}$. In both cases, the $0^{\circ}$ plies are along the longer dimension of the rectangular specimens, as shown schematically in Fig. 1. By reducing the specimen thickness from $3 \mathrm{~mm}$ to $2 \mathrm{~mm}$, the increased compliance of the thinner CF/PEEK specimens is predicted to lead to lower maximum impact loads, accompanied by longer impact event times, and 
higher displacements, and hence to less delamination damage occurring. Again, these predictions are indeed as would be expected [71].

\subsection{Summary}

The experimentally-measured and predicted values of the maximum load, impact duration time, maximum out-of-plane displacement, total energy dissipation and average areas of delamination footprint from the low-velocity impact tests, are given in Tables 5 and 6 for the CF/PEEK and CF/Epoxy composites, respectively. As may be seen, for both of these composites, there is a very good overall agreement between the experimental results and the predictions from the 3-D EP FEA model for the delamination areas and for the other important parameters that may be measured during the impact event. It should be noted, of course, that other numerical damage models may be found in the literature. For example, FEA numerical damage models which are 3-D and incorporate non-linear shear behaviour have also been shown to give good agreement with experimental results from low-velocity impact tests on CFRP plates and structures [e.g.1,4,8,10,15]. Nevertheless, the present model takes a somewhat different approach and models the 3-D EP behaviour of the composite material by incorporating the equivalent stress versus equivalent plastic strain relationships proposed by Sun et al. $[35,36]$. This approach has a firm physical basis and can account for anisotropic plasticity in the composite material. Furthermore, the present model incorporates the 3-D NU failure criteria [38-40,43-45] to determine the initiation of intralaminar damage such as matrix cracking, etc, and the NU criteria can readily model complex composite architectures including multidirectional ply lay-ups with woven layers. This combination of features in the proposed 3-D EP FEA damage model actually represents a novel approach and a methodology which it is considered will be of particularly benefit in future work when modelling the impact behaviour of adhesivelybonded repairs of CFRP composites. However, the proposed 3-D EP model clearly first needed to be validated against experimental data and this has been successfully achieved in the present paper.

\section{Conclusions}

In the present research, a three-dimensional (3-D) finite-element analysis (FEA) model incorporating an elastic-plastic (EP) damage model has been developed to predict accurately the impact behaviour of carbon-fibre fibre-reinforced (CFRP) composite laminates. To validate the model, experimental results have been obtained from relatively low-velocity impact tests on CFRP composite specimens employing either a matrix of a thermoplastic polymer, i.e. poly(ether-ether ketone), or a thermosetting epoxy polymer. The main findings are: 
- The model is able to predict very accurately the load versus time and the load versus displacement responses of the composite during the low-velocity drop-weight impact tests, including (a) the oscillations that arise in the rising load due to dynamic mass-spring effects and (b) the significant load drops, and associated subsequent oscillations, due to the initiation of intralaminar damage and interlaminar cracking. Indeed, the model predicts the overall impact behaviour of the composite specimens with a high degree of accuracy.

- The model, with its 3-D stress-state and EP material modelling capability, captures the through-thickness stress and strain responses, as well as the initiation and propagation of damage under the impactor, e.g. intralaminar matrix damage and interlaminar delaminations, i.e. interlaminar cracking, arising from the 3-D nature of the loading and the elastic-plastic response of the material.

- The 3-D EP FEA model captures accurately the localisation and degree of the permanent indentation in the composite specimen after impact and gives a quantitative value for this permanent indentation which is in very good agreement with the experimentally measured value, unlike a similar model which only considered the elastic response of the composite material.

- The 3-D EP FEA model predicts accurately the overall area of the delamination footprints of the impacted CF/PEEK and CF/Epoxy composite specimens, including the effects of steadily increasing the impact energy. Furthermore, the detailed extent, shape and orientation of this interlaminar cracking that occurs through the thickness of the composites have been predicted and shown to be in very good agreement with the experimental interlaminar delamination results as measured from the C-scan tests. However, when the threshold load for damage initiation is very close in value to the maximum load generated by the impact, there can be an uncertainty as to whether delaminations form, or not.

- The 3-D EP FEA model confirms that employing the relatively tough PEEK matrix reduces the extent of interlaminar delaminations for the CF/PEEK composite when subjected to a lowvelocity drop-weight impact, compared with the CF/Epoxy composite, in agreement with the experimental results.

In summary, the present FEA model takes in account the 3-D EP behaviour of the composite material by incorporating the equivalent stress versus equivalent plastic strain relationships, proposed by Sun et al. [35,36], to analyse anisotropic plasticity in the composite material. Also, the present 
FEA model employs the 3-D NU failure criteria [38-40], to determine the onset of the initiation of intralaminar damage such as matrix cracking, etc. As a result, the proposed 3-D EP FEA model can readily analyse failure processes in complex composite architectures including multidirectional ply layups with woven layers. This combination of features in the proposed 3-D EP FEA damage model actually represents a novel approach and a methodology which it is considered will be of particularly benefit in future work when modelling the impact behaviour of adhesively-bonded repairs of CFRP composites. However, the present 3-D EP model clearly first needed to be validated against experimental data and this has been successfully achieved in the present paper.

\section{Acknowledgments}

The present scientific research has received strong support from the Aviation Industry Corporation of China (AVIC) Manufacturing Technology Institute (MTI), the First Aircraft Institute (FAI), the Aircraft Strength Research Institute (ASRI) and the COMAC (Commercial Aircraft Corporation of China) BATRI (Beijing Aircraft Technology Research Institute), which is very much appreciated. The research was performed at the AVIC Centre for Structural Design and Manufacture in collaboration with the COMAC-Imperial Research Centre for Wing Technology of Commercial Aircraft, at Imperial College London, United Kingdom. The authors very much appreciate discussions with Dr. Soraia Pimenta, at Imperial College London, United Kingdom, and Professor Brian Falzon, FRAeS, at Queen's University Belfast, United Kingdom.

\section{Appendix A. The Elastic-Plastic (EP) Model of Sun et al. [35,36]}

\section{A.1. Introduction}

To establish the relationship between a complex stress state and a simple experimental stress state an equivalent stress, $\sigma_{\text {equ }}$, and equivalent plastic strain, $\varepsilon_{e q u}^{p}$, for modelling the plastic constitutive relationships between the stress and strain need to be derived.

\section{A.2. The equivalent stress, $\sigma_{\text {equ }}$}

A quadratic stress-based yield function, arising from the results of a micromechanical FEA approach, has been proposed for a general 3-D fibre-reinforced composite $[35,36]$ where:

$$
\begin{aligned}
2 f\left(\sigma_{i i}\right)= & a_{11} \sigma_{11}^{2}+a_{22} \sigma_{22}^{2}+a_{33} \sigma_{33}^{2}+2 a_{12} \sigma_{11} \sigma_{22} \\
& +2 a_{13} \sigma_{11} \sigma_{33}+2 a_{23} \sigma_{22} \sigma_{33} \\
& +2 a_{44} \tau_{23}^{2}+2 a_{55} \tau_{13}^{2}+2 a_{66} \tau_{12}^{2}
\end{aligned}
$$

and $f$ is the plastic potential. The coefficients, $a_{i j}(i, j=1,2,3,4,5,6)$ describe the extent of anisotropy in the composite material and are assumed to be constant. Now, Sun and Chen $[36,51,52]$ have simplified 
Eq. (A-1) by noting the fact that for most unidirectional fibre composites the stress versus strain relation in the fibre direction is basically linearly elastic and also by considering the composite to be transversely isotopic material in the 2-3 plane. Further, to establish the relationship between a complex stress state and a simple experimental stress state, they defined an equivalent stress for modelling the plastic constitutive relationship between the stress and the strain. Thus, the 3-D equivalent stress, $\sigma_{e q u}$, for a transversely isotopic composite, and which is linearly-elastic in the fibre direction, is given by $[48,50,72]$ :

$$
\sigma_{e q u}=\sqrt{\frac{3}{2}\left(\sigma_{22}^{2}+\sigma_{33}^{2}\right)-3 \sigma_{22} \sigma_{33}+3 a_{44} \tau_{23}^{2}+3 a_{55} \tau_{13}^{2}+3 a_{66} \tau_{12}^{2}}
$$

where $a_{44}, a_{55}$ and $a_{66}$ are coefficients indicating the extent of anisotropy in the plastic behaviour. For transversely isotropic composites which are linearly elastic in the fibre direction, i.e. a unidirectional fibre-reinforced composite, the value of the coefficient $a_{44}$, associated with the term $\tau_{23}^{2}$, can be set as having a value of two and the coefficient $a_{55}$, associated with $\tau_{13}^{2}$, is equal in value to the coefficient $a_{66}$, associated with $\tau_{12}^{2}$. Now, the coefficient $a_{66}$ can be readily determined from off-axis experiments conducted at different values of the off-axis angle using a unidirectional composite $[35,36,48]$, see below. However, it may also be noted that in off-axis tension tests of a unidirectional composite laminate a state of plane-stress will be present. Hence, the expression in Eq. (A-2) for the equivalent stress can be reduced to a 2-D version which gives $[35,36]$ :

$$
\sigma_{e q u}=\sqrt{\frac{3}{2} \sigma_{22}^{2}+3 a_{66} \tau_{12}^{2}}
$$

where the stresses are given by:

$$
\begin{aligned}
& \sigma_{11}=\cos ^{2} \theta \sigma_{X X} \\
& \sigma_{22}=\sin ^{2} \theta \sigma_{X X} \\
& \tau_{12}=-\sin \theta \cos \theta \sigma_{X X}
\end{aligned}
$$

and $\sigma_{X X}$ is the uniaxial applied stress in the loading direction, $X$, and $\theta$ is the off-axis angle, relative to the fibre direction, employed in the test. For tests with various off-axis angles, the in-plane stresses, $\sigma_{22}$ and $\tau_{12}$, and strains, $\varepsilon_{22}$ and $\gamma_{12}$, can be calculated using the applied stress, $\sigma_{X X}$, via substitution of Eqs. $(A-5)$ and $(A-6)$ into Eq. $(A-3)$ gives:

$$
\sigma_{e q u}=H(\theta) \sigma_{X X}
$$

where [36, 48]: 


$$
H(\theta)=\sqrt{\frac{3}{2} \sin ^{4} \theta+3 a_{66} \sin ^{2} \theta \cos ^{2} \theta}
$$

As will be shown later, the value of the coefficient, $a_{66}$, which is the only unknown term in Eq. (A-8), can be readily determined experimentally from off-axis tests conducted at different values of the off-axis angle, $\theta$, relative to the fibre direction. Thus, this allows the value of $\sigma_{\text {equ }}$ to be determined from Eq. (A-7).

\section{A.3. The equivalent plastic strain, $\varepsilon_{e q u}^{p}$}

The equivalent plastic strain, $\varepsilon_{e q u}^{p}$, gives a measure of the extent of plastic, i.e. non-linear, strain present in the composite. The total strain can be linearly decomposed into the elastic and plastic strains, assuming infinitesimal strain conditions, and for the normal strains may be expressed by:

$$
\varepsilon_{i i}=\varepsilon_{i i}^{e}+\varepsilon_{i i}^{p}
$$

and for the shear strains by:

$$
\tau_{i j}=\tau_{i j}^{e}+\tau_{i j}^{p}
$$

To define an equivalent plastic strain, $\varepsilon_{e q u}^{p}$, a similar approach to that adopted above for the equivalent stress may be followed [36] which gives:

$$
\varepsilon_{e q u}^{p}=\frac{\varepsilon_{X X}^{p}}{H(\theta)}
$$

where the term $H(\theta)$ is given by Eq. (A-8) and the term $\varepsilon_{X X}^{p}$ is the plastic strain resulting from the uniaxially applied load in the X-direction, which is given by:

$$
\varepsilon_{X X}^{p}=\varepsilon_{X X}-\frac{\sigma_{X X}}{E_{X X}}
$$

In the above equation, $E_{X X}$, is the elastic modulus in the loading direction which can be calculated from the material properties and off-axis angle employed in the test as given in $[36,72]$ :

$$
E_{X X}=\frac{1}{\frac{1}{E_{11}} \cos ^{4} \theta+\frac{1}{E_{22}} \sin ^{4} \theta+\left(\frac{1}{G_{12}}-\frac{2 v_{12}}{E_{11}}\right) \sin ^{2} \theta \cos ^{2} \theta}
$$

where $E_{11}$ and $E_{22}$ are the elastic moduli, $v_{12}$ is the Poisson's ratio and $G_{12}$ is the elastic shear modulus.

\section{A.4. Determination of the elastic-plastic constitutive relationship}

As noted above, off-axis experiments conducted at different values of the off-axis angle, relative to the fibre direction, using a unidirectional composite may be undertaken and either tensile or compressive stresses may be employed $[35,36,48]$. Based on the above equations, the experimental results for the equivalent stress versus equivalent plastic strain, i.e. $\sigma_{e q u}$ versus $\varepsilon_{e q u}^{p}$, relationships for 
different off-axis angles may then be extracted. In practice, it was noted that the experimental results for the equivalent stress versus equivalent plastic strain, i.e. $\sigma_{e q u}$ versus $\varepsilon_{e q u}^{p}$, relationship obtained from the $90^{\circ}$ off-axis specimen, were not influenced by the value of the coefficient $a_{66}$. Based on this observation, and using a trial and error method, the value of the single unknown coefficient, $a_{66}$, which enabled all of the experimental results for the equivalent stress versus equivalent plastic strain relationships from the $30^{\circ}, 45^{\circ}$ and $60^{\circ}$ off-axis tests to coincide with the results obtained from the $90^{\circ}$ off-axis test, was determined. Further, as shown by Sun et al. [36,51,72], all the experimental results for the equivalent stress versus equivalent plastic strain relationships, measured from such tests using different off-axis angles, $\theta$, could be fitted using a power law function, such that:

$$
\varepsilon_{\text {equ }}^{p}=A \sigma_{\text {equ }}^{n}
$$

where $A$ and $n$ are material constants. The determination of the one unknown coefficient, $a_{66}$, and the constants, $A$ and $n$, allow the calculation of the incremental plastic strains, $d \varepsilon_{i j}^{p}$ and $d \gamma_{i j}^{p}(i, j=1,2,3)$, as given by:

$$
\left\{\begin{array}{l}
d \varepsilon_{11}^{p} \\
d \varepsilon_{22}^{p} \\
d \varepsilon_{33}^{p} \\
d \gamma_{12}^{p} \\
d \gamma_{13}^{p} \\
d \gamma_{23}^{p}
\end{array}\right\}=\frac{A n}{\sigma_{e q u}{ }^{1-n}}\left\{\begin{array}{c}
3\left(\sigma_{22}-\sigma_{33}\right) / 2 \sigma_{\text {equ }} \\
3\left(\sigma_{33}-\sigma_{22}\right) / 2 \sigma_{\text {equ }} \\
3 a_{66} \tau_{12} / 2 \sigma_{\text {equ }} \\
3 a_{66} \tau_{13} / 2 \sigma_{\text {equ }} \\
6 \tau_{23} / 2 \sigma_{\text {equ }}
\end{array}\right\} d \sigma_{\text {equ }}
$$

Hence, the complete constitutive relationship can now be obtained by combining the classical elastic model and the plastic model to give:

$$
\left\{\begin{array}{l}
d \varepsilon_{11} \\
d \varepsilon_{22} \\
d \varepsilon_{33} \\
d \gamma_{12} \\
d \gamma_{13} \\
d \gamma_{23}
\end{array}\right\}=\left[\begin{array}{cccccc}
1 / E_{11} & -v_{21} / E_{11} & -v_{31} / E_{11} & 0 & 0 & 0 \\
-v_{12} / E_{22} & 1 / E_{22} & -v_{32} / E_{22} & 0 & 0 & 0 \\
-v_{13} / E_{33} & -v_{23} / E_{33} & 1 / E_{33} & 0 & 0 & 0 \\
0 & 0 & 0 & 1 / G_{12} & 0 & 0 \\
0 & 0 & 0 & 0 & 1 / G_{13} & 0 \\
0 & 0 & 0 & 0 & 0 & 1 / G_{23}
\end{array}\right]\left\{\begin{array}{l}
d \sigma_{11} \\
d \sigma_{22} \\
d \sigma_{33} \\
d \tau_{12} \\
d \tau_{13} \\
d \tau_{23}
\end{array}\right\}+\left\{\begin{array}{l}
d \varepsilon_{11}^{p} \\
d \varepsilon_{22}^{p} \\
d \varepsilon_{33}^{p} \\
d \gamma_{12}^{p} \\
d \gamma_{13}^{p} \\
d \gamma_{23}^{p}
\end{array}\right\}
$$

where $d \varepsilon_{i j}^{p}$ and $d \gamma_{i j}^{p}(i, j=1,2,3)$ are the incremental plastic strains, and $d \varepsilon_{i j}$ and $d \gamma_{i j}(i, j=1,2,3)$ are the incremental total strains and $d \sigma_{i j}$ and $d \tau_{i j}(i, j=1,2,3)$ are the incremental stresses. The parameters $v_{i j}(i, j=1,2,3, i \neq j)$ are the Poisson's ratios, $E_{i i}(i, j=1,2,3, i=j)$ are the Young's moduli either for tension or compression loading, which are generally considered to be similar for composite laminates [25], and $G_{i j}(i, j=1,2,3, i \neq j)$ are the shear moduli.

\section{References}

[1] Hou JP, Petrinic N, Ruiz, C, Hallett SR. Prediction of impact damage in composite plates. Compos Sci Technol, 2000;60:273-81. 
[2] de Moura MFSF, Goncalves JPM. Modelling the interaction between matrix cracking and delamination in carbon-epoxy laminates under low velocity impact. Compos Sci Technol, 2004;64:1021-27.

[3] Kashtalyan M, Soutis C. Analysis of composite damage with intra- and interlaminar damage. Prog Aerospace Sci, 2005:41:152-73.

[4] Donadon MV, lannucci L, Falzon BG, Hodgkinson JM, de Almeida SFM. A progressive failure model for composite laminates subjected to low velocity impact damage. Compos Struct, 2008;86:1232-52.

[5] Bouvet C, Castanie, B, Bizeul M, Barrau, JJ. Low velocity impact modelling in laminate composite panels with discrete interface elements. Intern J Solids Struct, 2009;46:2809-21.

[6] Lopes CS, Camanho PP, Gurdal Z, Maimi P, Gonzalez EV. Low-velocity impact damage on dispersed stacking sequence laminates. Part II: Numerical simulations. Compos Sci Technol, 2009;69:937-47.

[7] Faggiani A, Falzon BG. Predicting low-velocity impact damage on a stiffened composite panel. Compos Part A, 2010;41:737-49.

[8] Batra RC, Gopinath G, Zheng, JQ. Damage and failure in low energy impact of fiber-reinforced polymeric composite laminates Compos Struct, 2012;94:540-47.

[9] Bouvet C, Rivallant S, Barrau JJ. Low velocity impact modeling in composite laminates capturing permanent indentation. Compos Sci Technol, 2012;72:1977-88.

[10] Shi Y, Swait T, Soutis C. Modelling damage evolution in composite laminates subjected to low velocity impact. Compos Struct, 2012;94:2902-13.

[11] Hongkarnjanakul N, Bouvet C, Rivallant S. Validation of low velocity impact modelling on different stacking sequences of CFRP laminates and influence of fibre failure. Compos Struct, 2013;106:549-59.

[12] Dang TD, Hallett, SR. A numerical study on impact and compression after impact behaviour of variable angle tow laminates. Compos Struct, 2013;96:194-206.

[13] Shi Y, Pinna C, Soutis C. Modelling impact damage in composite laminates: A simulation of intra-and inter-laminar cracking. Compos Struct, 2014;114:10-9.

[14] Feng D, Aymerich F. Finite element modelling of damage induced by low-velocity impact on composite laminates. Compos Struct, 2014;108:161-71.

[15] Tan W, Falzon BG, Chiu, LNS, Price M. Predicting low velocity impact damage and compression-afterimpact (CAI) behaviour of composite laminates. Compos Part A, 2015;71:212-26.

[16] Sun XC, Hallett SR. Barely visible impact damage in scaled composite laminates: Experiments and numerical simulations. Int J Impact Eng, 2017;109:178-95

[17] Liu H, Falzon BG, Tan W. Experimental and numerical studies on the impact response of damage tolerant hybrid unidirectional/woven carbon-fibre reinforced composite laminates. Compos Part B, 2018;136:10118.

[18] Liu H, Falzon BG, Tan W. Predicting the compression-after-impact (CAI) strength of damage-tolerant hybrid unidirectional/woven carbon-fibre reinforced composite laminates. Compos Part A, 2018;105:189202.

[19] Zhou J, Wen P, Wang S. Finite element analysis of a modified progressive damage model for composite laminates under low-velocity impact. Compos Struct, 2019;225:111113.

[20] Liu H, Liu J, Kaboglu C, Chai H, Kong X, Blackman BRK, Kinloch AJ, Dear JP. Experimental investigations on the effects of projectile hardness on the impact response of fibre reinforced composite laminates. Int J Lightweight Mater Manuf, 2020;3:77-87.

[21] Liu H, Liu J, Kaboglu C, Zhou J, Kong X, Blackman BRK, Kinloch AJ, Dear JP. The behaviour of fibrereinforced composites subjected to a soft impact-loading: An experimental and numerical study. Eng Fail Anal, 2020;111:104448.

[22] Liu H, Liu J, Ding Y, Zheng J, Kong X, Zhou J, Harper L, Blackman BRK, Kinloch AJ, Dear JP. The behaviour of thermoplastic and thermoset carbon-fibre composites subjected to low-velocity and highvelocity impact. J Mats Sci, 2020; to be published.

[23] Hashin A, Rotem A. Fatigue failure criterion for fiber reinforced materials. J Compos Mater, 1973;7:44864.

[24] Hashin Z. Failure criteria for unidirectional fiber composites. J Appl Mech, 1980;47: 329-34.

[25] Abaqus 2018 documentation, Dassault Systèmes, Provid. Rhode Island, USA. (2018).

[26] Brewer JC, Lagace PA. Quadratic stress criterion for initiation of delamination. J Compos Mater, 1988;22:1141-96.

[27] Dugdale DS. Yielding of steel sheets containing slits. J Mech Phys Solids, 1960;8:100-4.

[28] Barenblatt GI. The mathematical theory of equilibrium cracks in brittle fracture. Adv Appl Mech, 1962;7:55129.

[29] Shi Y, Pinna C, Soutis C. Interface cohesive elements to model matrix crack evolution in composite laminates. Appl Compos Mater, 2014;21:57-70. 
[30] Turon A, Davila C, Camanho P, Costa J. An engineering solution for mesh size effects in the simulation of delamination using cohesive zone models. Eng Fract Mech, 2007;74:1665-82.

[31] Benzeggagh M, Kenane M. Measurement of mixed-mode delamination fracture toughness of unidirectional glass/epoxy composites with mixed-mode bending apparatus. Compos Sci Technol, 1996;56:439-49.

[32] Camanho P, Davila C, De Moura M. Numerical simulation of mixed-mode progressive delamination in composite materials. J Compos Mater, 2003;37:1415-38.

[33] Berbinau P, Soutis C, Goutas P, Curtis PT. Effect of off-axis ply orientation on $0^{\circ}$ fibre microbuckling. Composites Part A, 1999;30:1197-207.

[34] Berbinau P, Soutis C, Guz IA. Compressive failure of $0^{\circ}$ unidirectional carbon fibre-reinforced plastic (CFRP) laminates by fibre micobuckling. Compos Sci Technol, 1999;59:1451-5.

[35] Chen JK, Allahdadi FA, Sun CT. A quadratic yield function for fiber-reinforced composites. J Compos Mater, 1997;31:788-811.

[36] Sun CT, Chen JL. A Simple Flow Rule for Characterizing Nonlinear Behavior of Fiber Composites. J Compos Mater, 1989;23:1009-20.

[37] Chen JF, Morozov EVShankar K. A combined elastoplastic damage model for progressive failure analysis of composite materials and structures. Compos Struct, 2012;94:3478-89.

[38] Daniel IM, Luo J, Schubel PM. Three-dimensional characterization of textile composites. Comp Part B, 2008;39:13-9.

[39] Daniel IM, Luo J, Schubel PM, Werner BT. Interfiber/interlaminar failure of composites under multi-axial states of stress. Compos Sci Technol, 2009;69:764-71.

[40] Daniel IM. Failure of composite materials. Strain, 2007;43:4-12.

[41] Leong M, Overgaard LCT, Thomsen OT, Lund E, Daniel IM. Investigation of failure mechanisms in GFRP sandwich structures with face sheet wrinkle defects used for wind turbine blades. Compos Struct, 2012;94:768-78.

[42] Leong M, Overgaard LCT, Daniel IM, Lund E, Thomsen OT. Interlaminar/interfiber failure of unidirectional glass fiber reinforced composites used for wind turbine blades. J Compos Mater, 2012;47:353-68.

[43] Daniel IM, Werner BT, Fenner JS. Strain-rate-dependent failure criteria for composites. Compos Sci Technol, 2011;71:357-64.

[44] Daniel IM. Failure of composite materials under multi-axial static and dynamic loading. Procedia Eng 2014; 88:10-7.

[45] Jacobsen AJ, Luo JJ, Daniel IM. Characterization of constitutive behavior of satin-weave fabric composite. J Compos Mater, 2004;38:555-65.

[46] Puck P, Schurmann H. Failure analysis of FRP laminates by means of physically based phenomenological models. Compos Sci Technol, 1998;58:1045-67

[47] Liu J. The Performance of Thermoplastic and Thermoset Composites Subjected to Impact Loading. PhD Thesis. Imperial College London, UK, 2020.

[48] Yokozeki T, Ogihara S, Yoshida S, Ogasawara T. Simple constitutive model for nonlinear response of fiber-reinforced composites with loading-directional dependence. Compos Sci Technol, 2007;67:111-8.

[49] Gates TS, Sun CT. Elastic/Viscoplastic Constitutive Model for Fiber Reinforced Thermoplastic Composites. AIAA J, 1991;29:457-63.

[50] Weeks CA, Sun CT. Modeling non-linear rate-dependent behavior in fiber-reinforced composites. Compos Sci Technol, 1998;58:603-11.

[51] Sun CT, Rui Y. Orthotropic elasto-plastic behavior of AS4/PEEK thermoplastic composite in compression. Mech Mater, 1990;10:117-25.

[52] Yoon KJ, Sun CT. Characterization of elastic-viscoplastic properties of an AS4/PEEK thermoplastic composite. J Compos Mater, 1991;25:1277-96.

[53] Liu H, Liu J, Ding Y, Zhou J, Kong X, Blackman BRK, Kinloch AJ, Falzon BG, Dear JP. Effects of impactor geometry on the low-velocity impact behaviour of fibre-reinforced composites: an experimental and theoretical investigation. Appl Comp Mater, 2020; to be published.

[54] Liu H, Falzon BG, Li S, Tan W, Liu J, Chai H, Blackman BRK, Dear JP. Compressive failure of woven fabric reinforced thermoplastic composites with an open-hole: An experimental and numerical study. Compos Struct, 2019; 213:108-17.

[55] Turon A, Camanho P, Costa J, Renart J. Accurate simulation of delamination growth under mixed-mode loading using cohesive elements: definition of interlaminar strengths and elastic stiffness. Compos Struct, 2010;92:1857-64.

[56] Sarrado C, Turon A, Renart J, Urresti I. Assessment of energy dissipation during mixed-mode delamination growth using cohesive zone models. Compos Part A, 2012;43:2128-36. 
[57] Hashemi S, Kinloch A, Williams JG. The analysis of interlaminar fracture in uniaxial fibrEPolymer composites. Proc R Soc London A, 1990;427:173-99.

[58] Liu H, Liu J, Kaboglu C, Chai H, Kong X, Blackman BRK, Kinloch AJ, Dear JP. Experimental and numerical studies on the behaviour of fibre-reinforced composites subjected to soft impact loading. Procedia Struct Integr, 2019;17:992-1001.

[59] Falzon BG, Liu H, Tan W. Comment on 'A tensorial based progressive damage model for fibre reinforced polymers'. Compos Struct, 2017;176:877-82.

[60] Chiu LNS, Falzon BG, Ruan D, Xu S, Thomson RS, Chen B, Yan W. Crush responses of composite cylinder under quasi-static and dynamic loading. Compos Struct, 2015;131:90-8.

[61] Liu H, Falzon BG, Dear JP. An experimental and numerical study on the crush behaviour of hybrid unidirectional/woven carbon-fibre reinforced composite laminates. Int J Mech Sci, 2019;164:105160.

[62] Abir MR, Tay TE, Ridha M, Lee HP. On the relationship between failure mechanism and compression after impact (CAI ) strength in composites. Compos Struct, 2017;182:242-50.

[63] Dear JP, MacGillivray JH. Strain gauging for accurate determination of $\mathrm{K}$ and $\mathrm{G}$ in impact tests. J Mater Sci, 1991;26:2124-32.

[64] Crouch BA, Williams JG. Modelling of dynamic crack propagation behaviour in the threEPoint bend impact specimen. J Mech Phys Solids, 1988;36:1-13.

[65] Williams JG, Adams GC. The analysis of instrumented impact tests using a mass-spring model. Int J Fract, 1987;33:209-22.

[66] Dear JP. High speed photography of impact effects in threEPoint bend testing of polymers. J Appl Phys, 1990;67:4304-12.

[67] Bieniaś J, Jakubczak P, Surowska B. Comparison of polymer composites behavior to low-velocity impact and quasi-static indentation. Composites Theory and Practice. 2013;13:155-9.

[68] Topac OT, Gozluklu B, Gurses E, Coker D. Experimental and computational study of the damage process in CFRP composite beams under low-velocity impact Compos Part A, 2017;92:167-82.

[69] Talreja R, Phan N. Assessment of damage tolerance approaches for composite aircraft with focus on barely visible impact damage. Compos Struct, 2019;219:1-7.

[70] Roy CJ. Review of code and solution verification procedures for computational simulation. J Comput Phys, 2005;205:131-156.

[71] Belingardi G, Vadori, R. Influence of the laminate thickness in low velocity impact behavior of composite material plate. Compos Struct, 2003;61:27-38.

[72] Sun CT, Yoon KJ. Characterization of elastic-plastic behavior of AS4/PEEK thermoplastic composite for temperature variation. J Compos Mater, 1991;25:1297-1313.

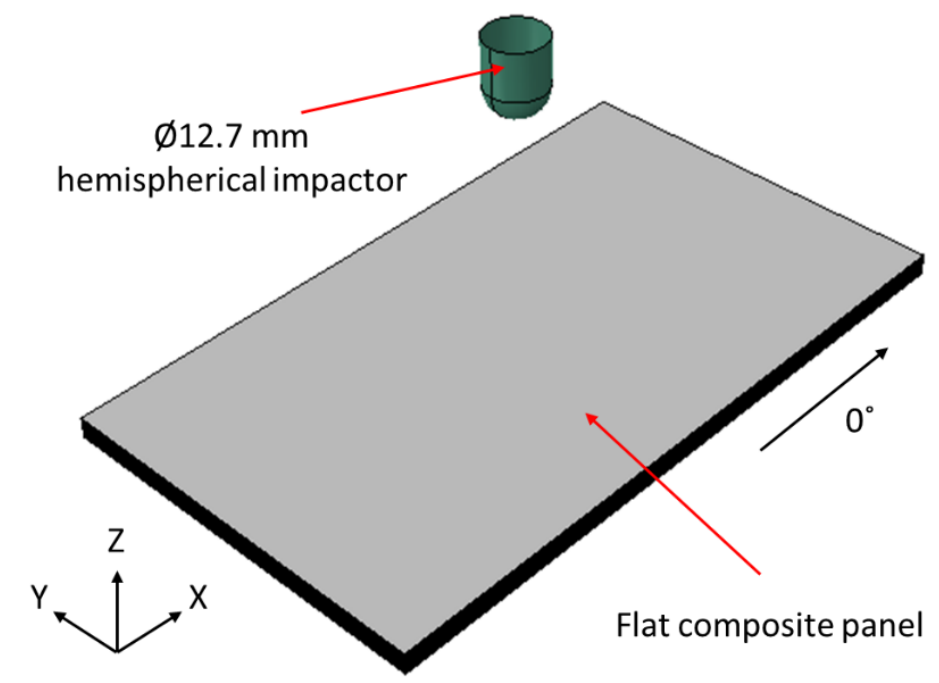

Fig. 1. Schematic of the CF/PEEK and CF/Epoxy composite test specimens with dimensions of $150 \times 100 \mathrm{~mm}$. (The arrow indicates the fibre direction of the $0^{\circ}$ fibres.) 


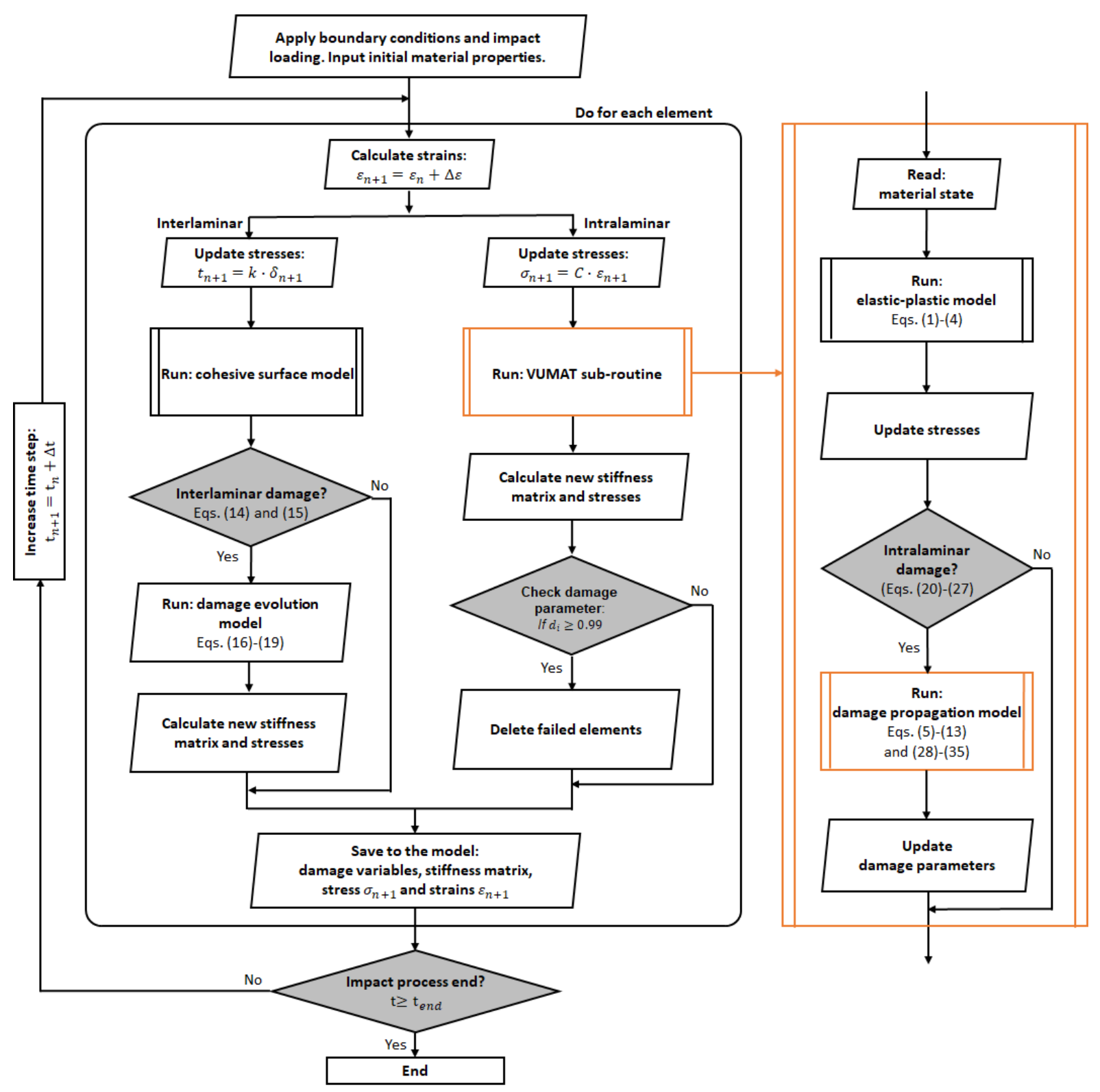

Fig. 2. The implementation of the 3-D EP FEA numerical model showing schematically the overall flowchart for one computational time-step and a single integration point. Both the flowcharts for the main model and for the elastic-plastic (EP) 'VUMAT' sub-routine are shown. This FEA modelling simulation of the impact event would be run typically over a time-scale, $\mathrm{t}$, of 0 to ca. $6 \mathrm{~ms}$, with ca. 100 time-steps being employed. The simulation runs were stopped when the defined total computation time for the impact simulation event had expired. 


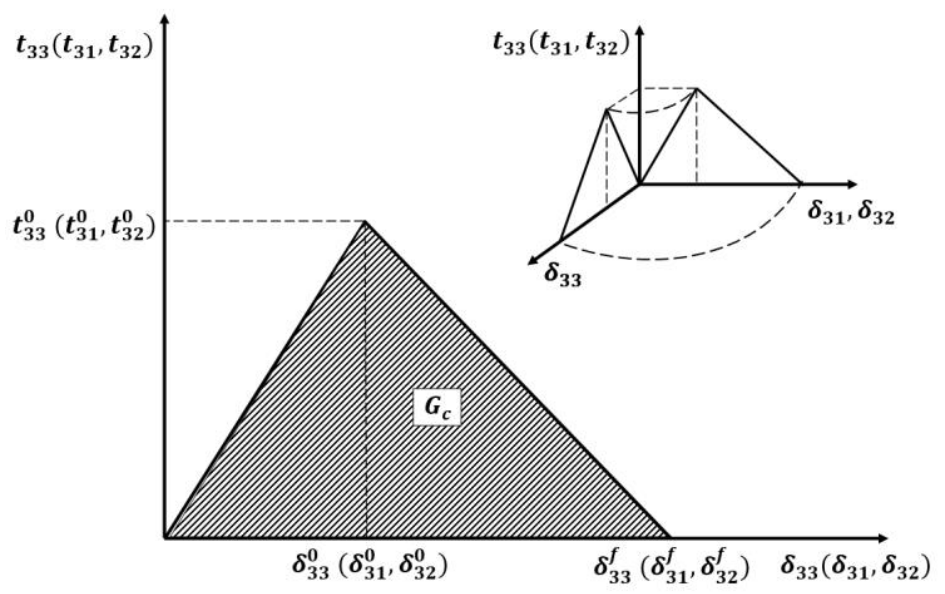

Fig. 3. Schematic of the traction versus separation response for the cohesive surface law for modelling the interlaminar damage. 


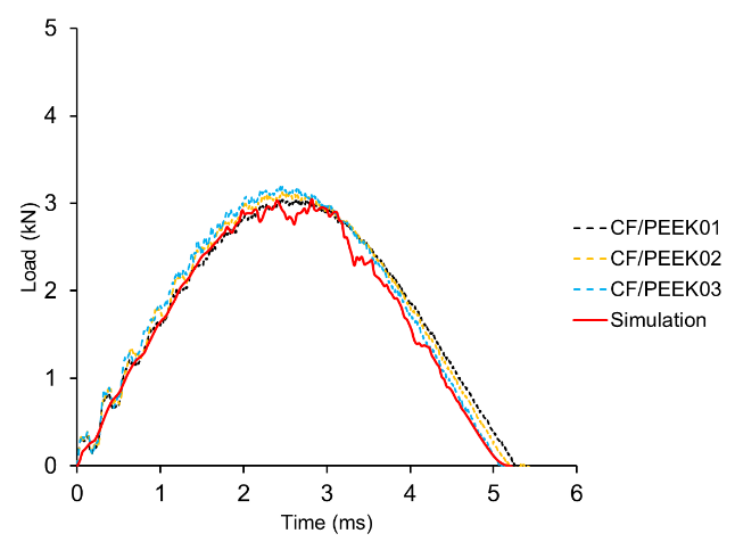

(a) $(\mathrm{IE}=4.5 \mathrm{~J})$

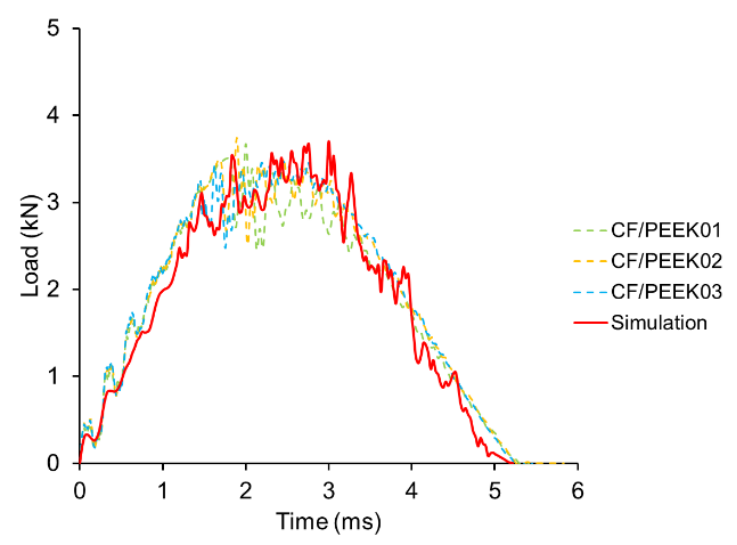

(c) $(\mathrm{IE}=7.5 \mathrm{~J})$

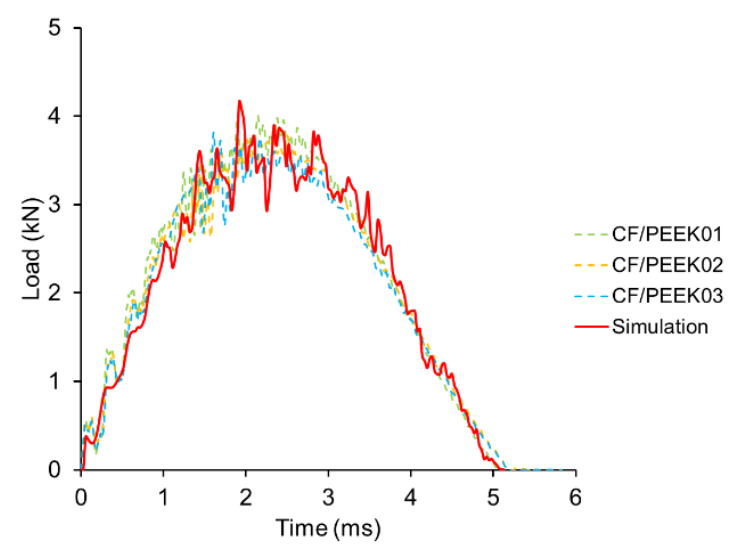

(e) $(\mathrm{IE}=10.5 \mathrm{~J})$

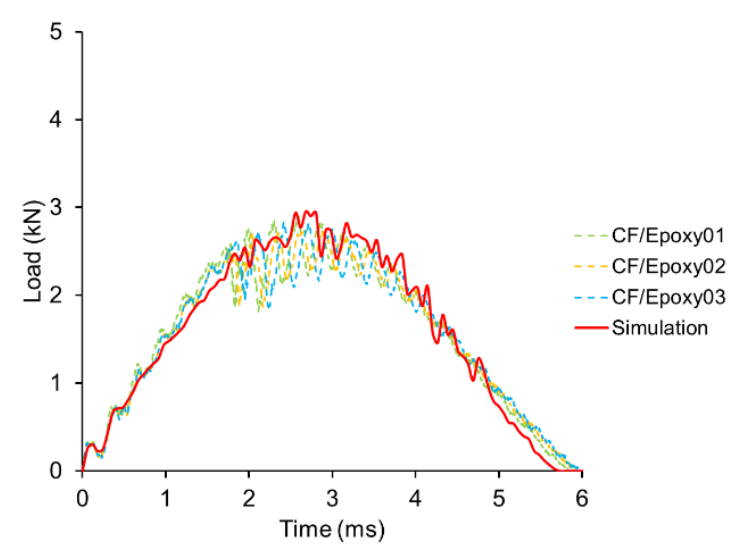

(b) $(\mathrm{IE}=4.5 \mathrm{~J})$

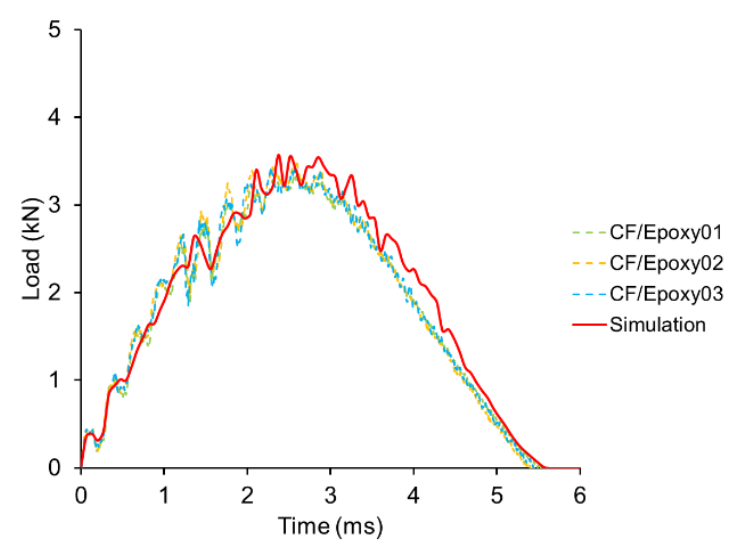

(d) $(\mathrm{IE}=7.5 \mathrm{~J})$

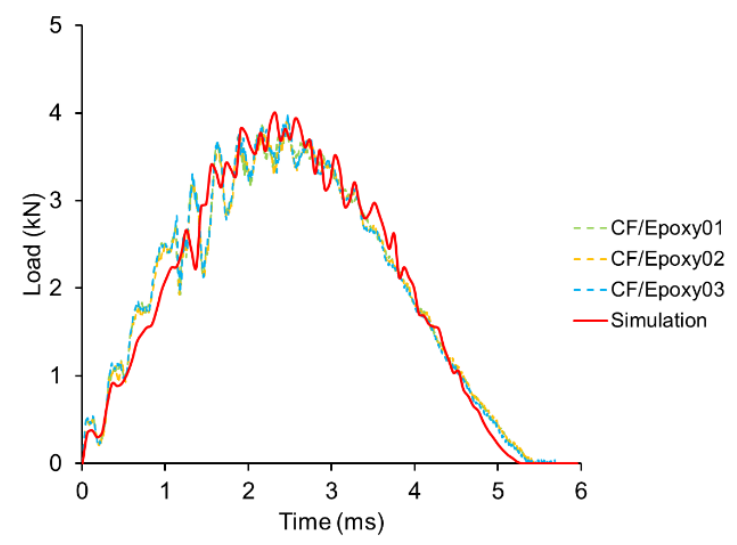

(f) (IE=10.5 J)

Fig. 4. Experimental and predicted load versus time curves for the CF/PEEK composite specimens at: (a) 4.5, (c) 7.5 and (e) $10.5 \mathrm{~J}$ impact energy levels, and for the CF/Epoxy composite specimens at: (b) 4.5, (d) 7.5 and (f) $10.5 \mathrm{~J}$ impact energy levels. (The corresponding impact velocities were $1.68,2.16$ and $2.56 \mathrm{~m} . \mathrm{s}^{-1}$, respectively. Experimental results from the three replicate tests are shown.) 


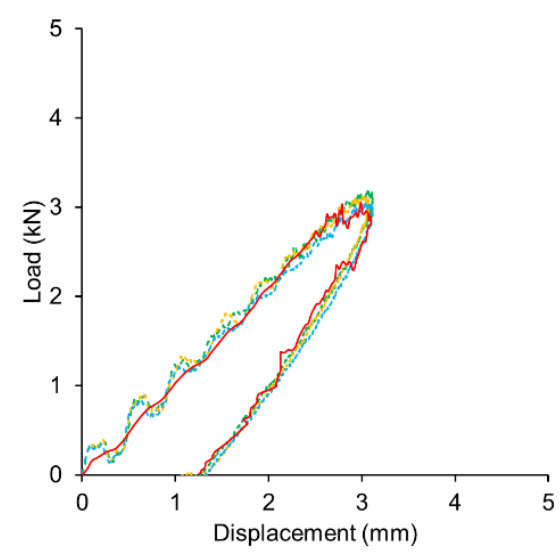

(a) $(\mathrm{IE}=4.5 \mathrm{~J})$

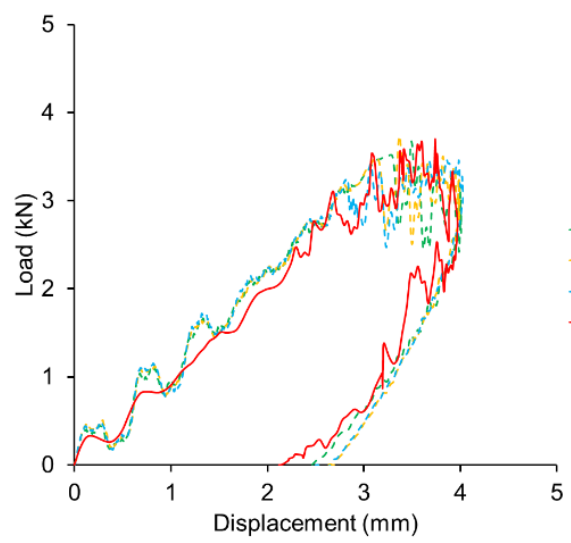

(c) $(\mathrm{IE}=7.5 \mathrm{~J})$

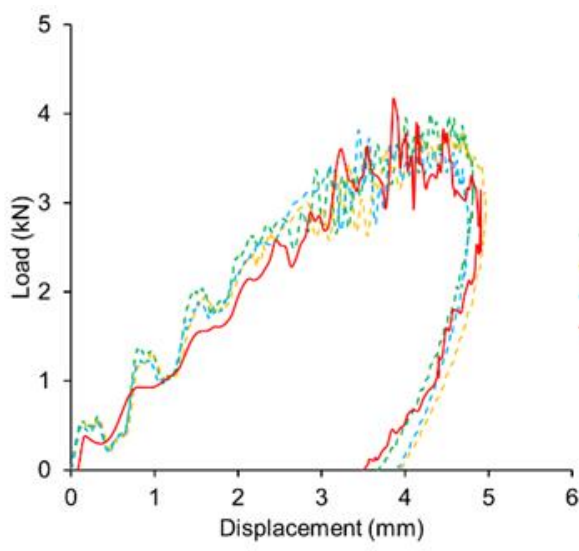

(e) $(\mathrm{IE}=10.5 \mathrm{~J})$

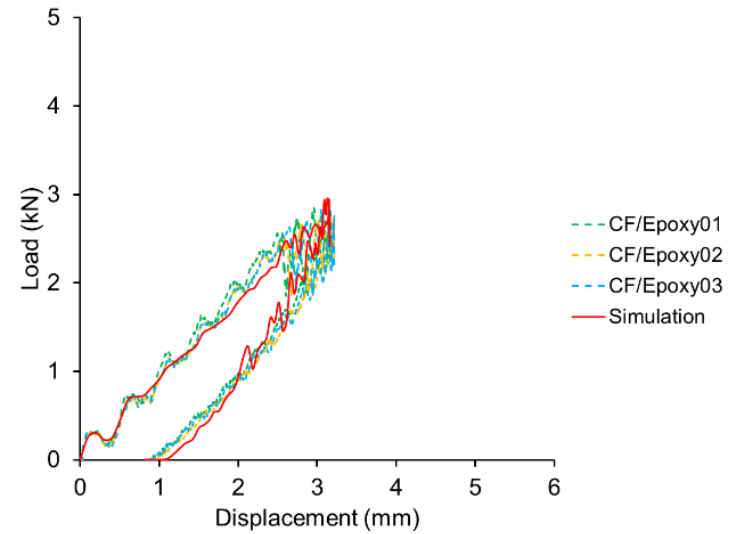

(b) $(\mathrm{IE}=4.5 \mathrm{~J})$

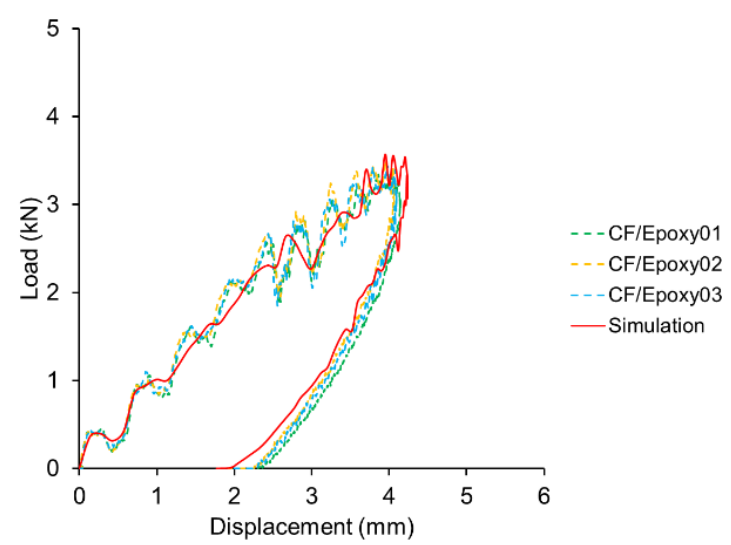

(d) $(\mathrm{IE}=7.5 \mathrm{~J})$

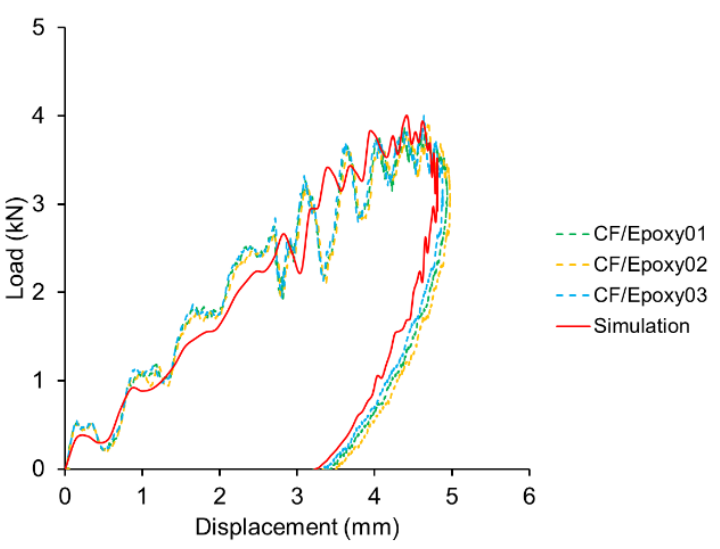

(f) $(\mathrm{IE}=10.5 \mathrm{~J})$

Fig. 5. Experimental and predicted load versus displacement curves for the CF/PEEK composite specimens at: (a) 4.5, (c) 7.5 and (e) $10.5 \mathrm{~J}$ impact energy levels, and for the CF/Epoxy composite specimens at: (b) 4.5, (d) 7.5 and (f) $10.5 \mathrm{~J}$ impact energy levels. (The corresponding impact velocities were $1.68,2.16$ and $2.56 \mathrm{~m}^{-1} \mathrm{~s}^{-1}$, respectively. Experimental results from the three replicate tests are shown.) 


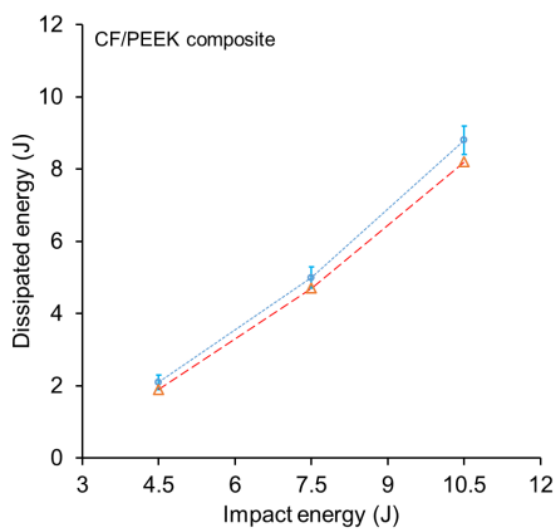

(a)

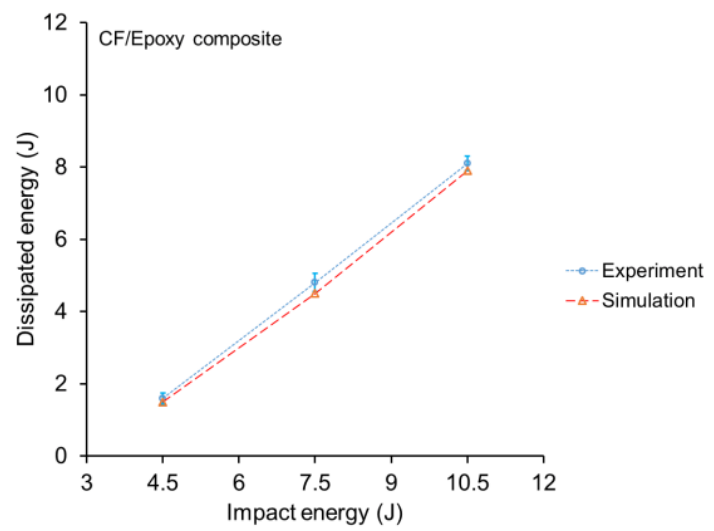

(b)

Fig. 6. Comparison between the average experimental and predicted energy dissipation versus the impact energy relationships for: (a) the CF/PEEK composite specimens and (b) the CF/Epoxy composite specimens.

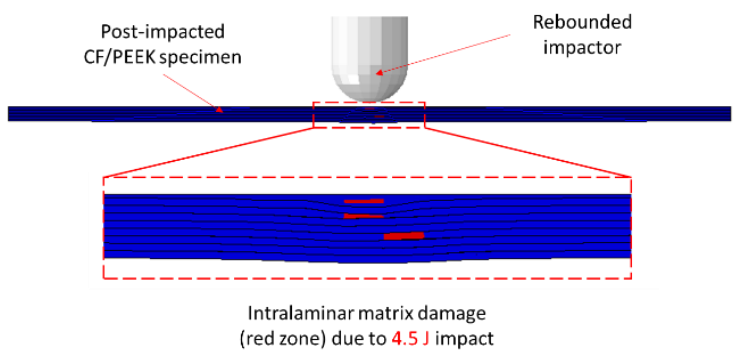

(a)

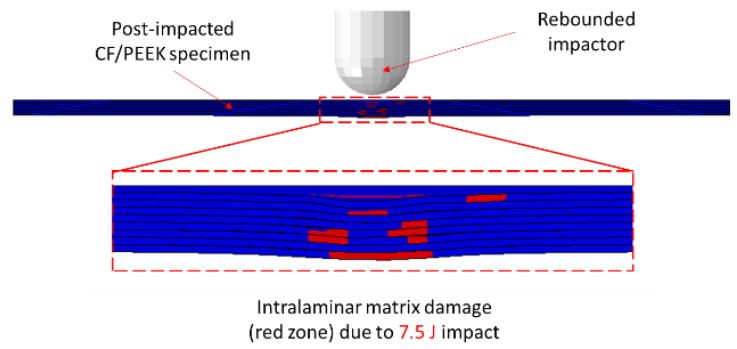

(c)

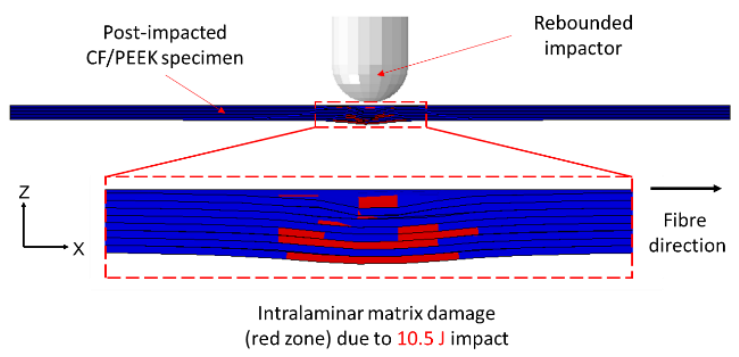

(e)

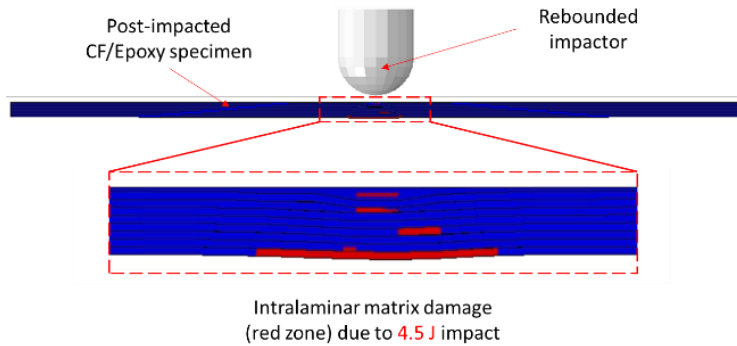

(b)

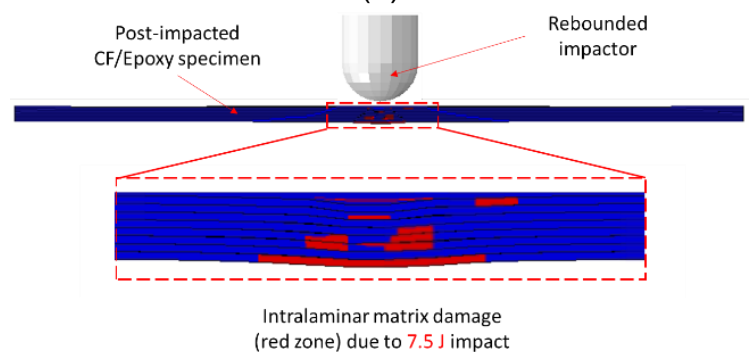

(d)

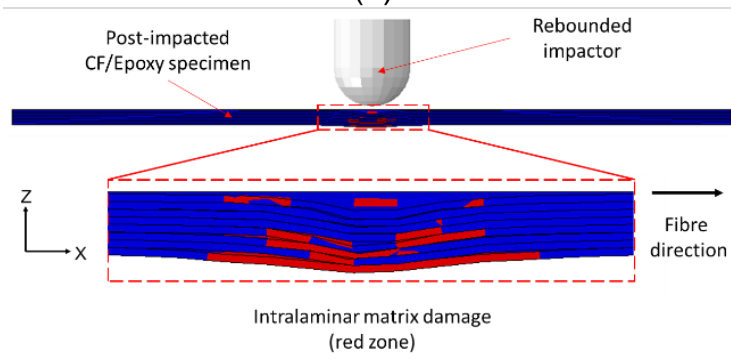

(f)

Fig. 7. Predicted intralaminar damage for the CF/PEEK composite specimens at: (a) 4.5, (c) 7.5 and (e) $10.5 \mathrm{~J}$ impact energy levels, and for the CF/Epoxy composite specimens at: (b) 4.5, (d) 7.5 and (f) $10.5 \mathrm{~J}$ impact energy levels. (The predicted intralaminar damage is shown as the redcoloured areas.) 


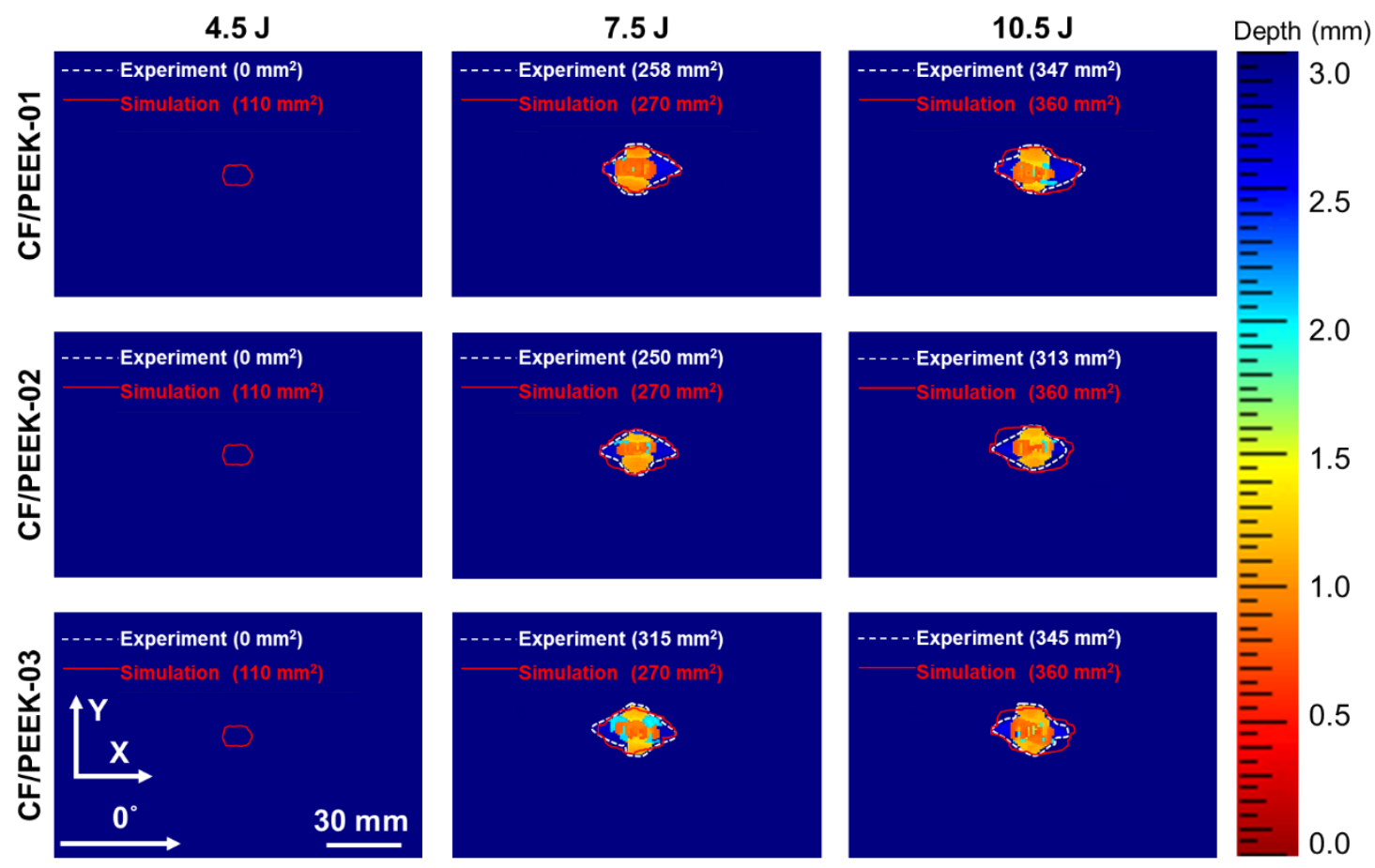

Fig. 8. Comparison between the experimentally-measured and the predicted footprint areas of the interlaminar delaminations, i.e. interlaminar cracking, for the CF/PEEK composite specimens impacted at 4.5, 7.5 and $10.5 \mathrm{~J}$. (Experimental results from the three replicate tests are shown.)

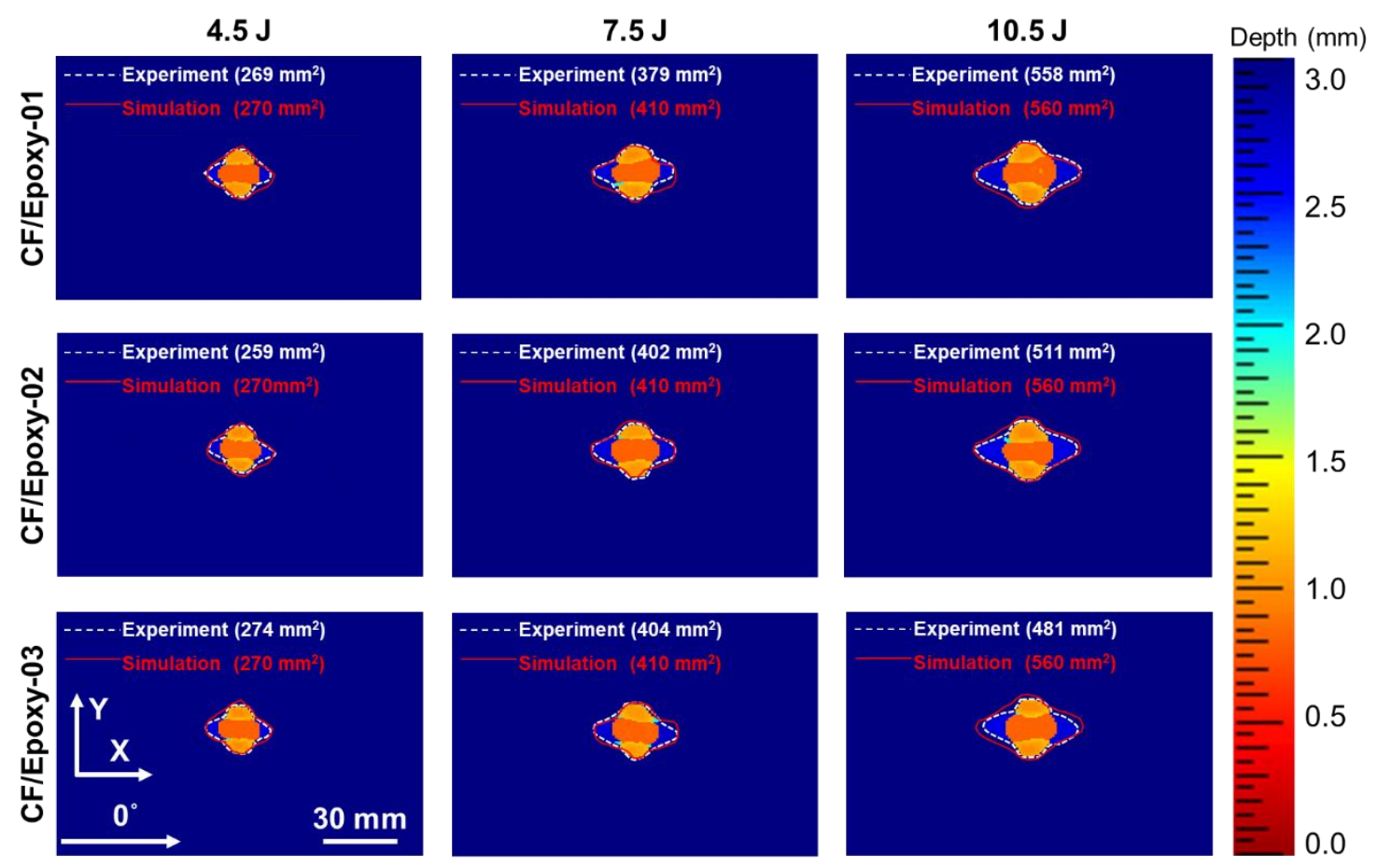

Fig. 9. Comparison between the experimentally-measured and the predicted footprint areas of the interlaminar delaminations, i.e. interlaminar cracking, for the CF/Epoxy composite specimens impacted at 4.5, 7.5 and $10.5 \mathrm{~J}$. (Experimental results from the three replicate tests are shown.) 


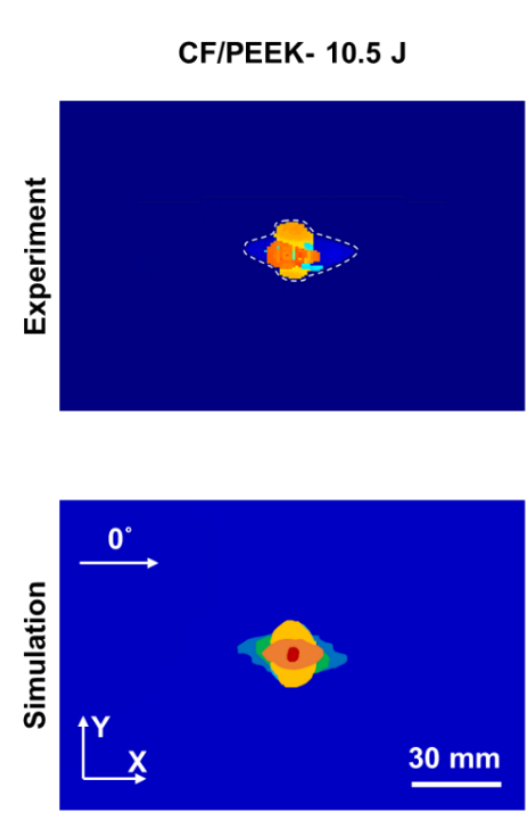

(a)

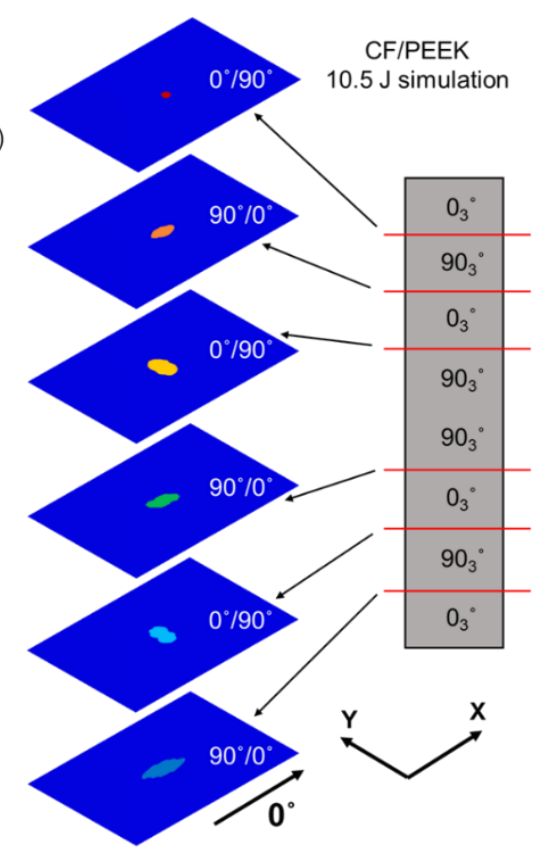

(b)

Fig. 10. Comparison between the experimentally-measured (test replicate-01) and the predicted interlaminar delaminations, i.e. interlaminar cracking, for the CF/PEEK composite specimens at an impact energy of $10.5 \mathrm{~J}$ : (a) the experimental and predicted footprint areas of the delaminations and (b) the exploded view of the predicted areal delaminations.

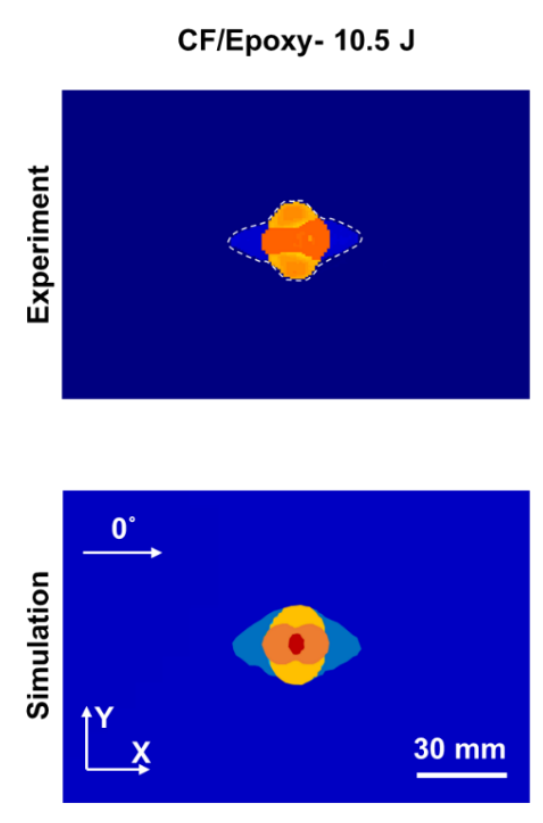

(a)

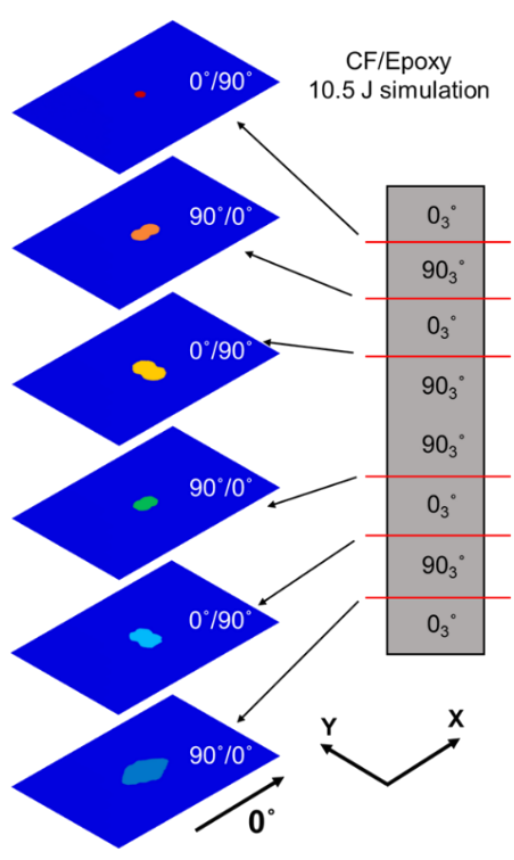

(b)

Fig. 11. Comparison between the experimentally-measured (test replicate-01) and the predicted interlaminar delaminations, i.e. interlaminar cracking, for the CF/Epoxy composite specimens at an impact energy of $10.5 \mathrm{~J}$ : (a) the experimental and predicted footprint areas of delaminations and (b) the exploded view of the predicted areal delaminations. 

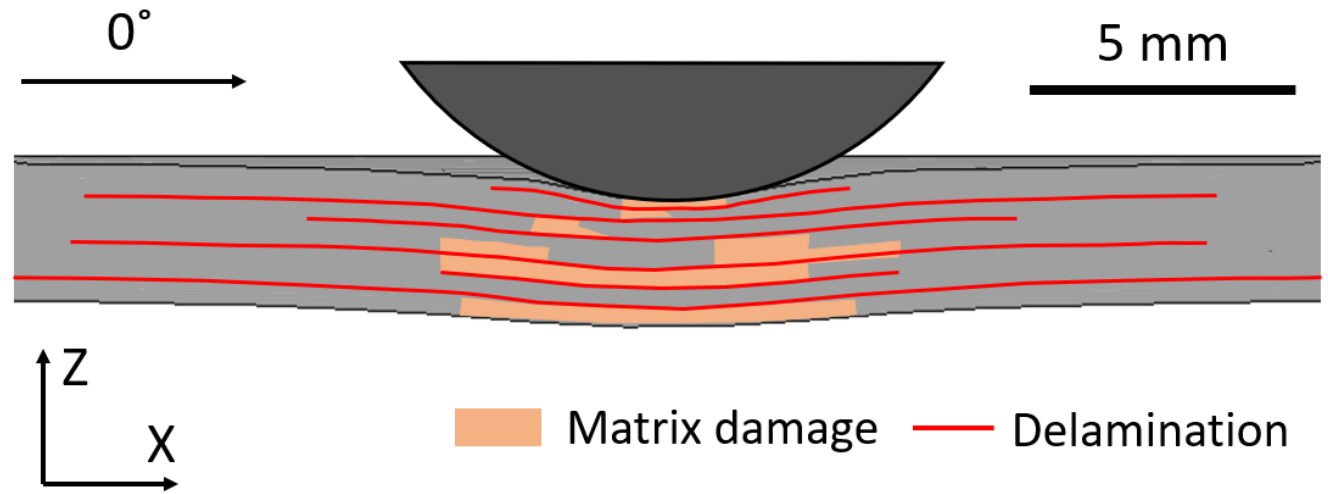

\section{Matrix damage - Delamination}

Fig. 12. The interactions of intralaminar matrix cracking and interlaminar cracking when damage has fully propagated in the CF/PEEK composite specimens when tested at an impact energy of $10.5 \mathrm{~J}$. (The impact event time is $\mathrm{t}=3 \mathrm{~ms}$.)

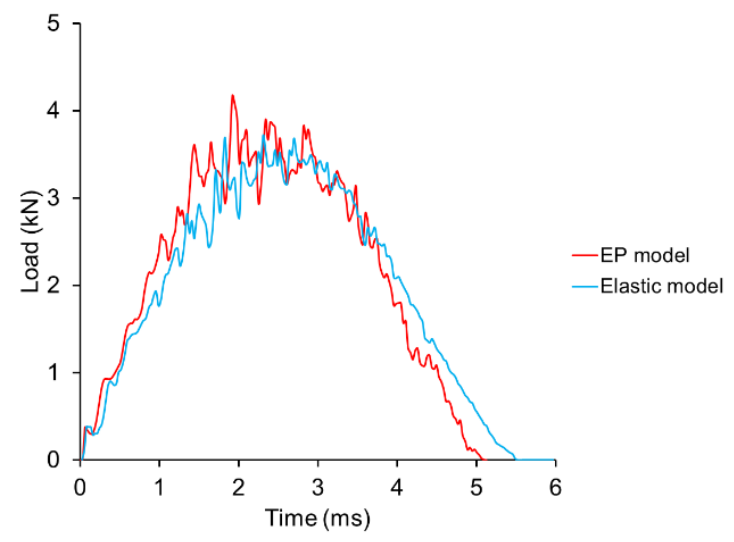

(a)

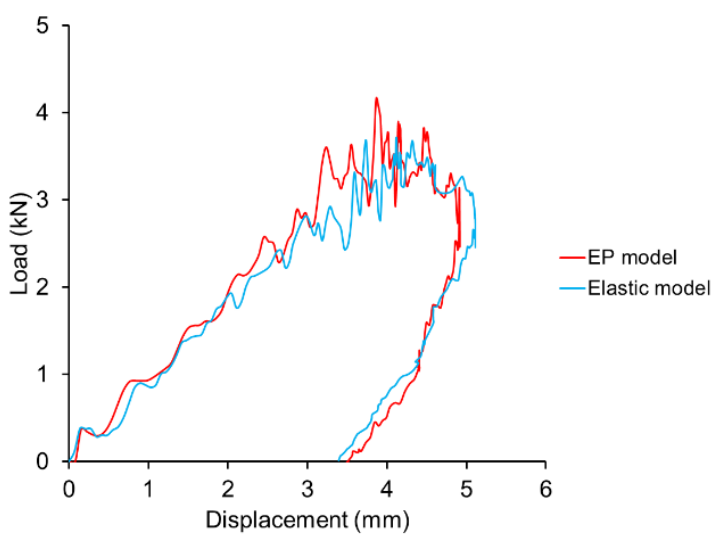

(b)

Fig. 13. (a) Load versus time and (b) load versus displacement curves obtained for the CF/PEEK composite specimens at an impact energy of $10.5 \mathrm{~J}$ from the 3-D EP model and the 3-D Elastic only model.

\section{3-D EP model}

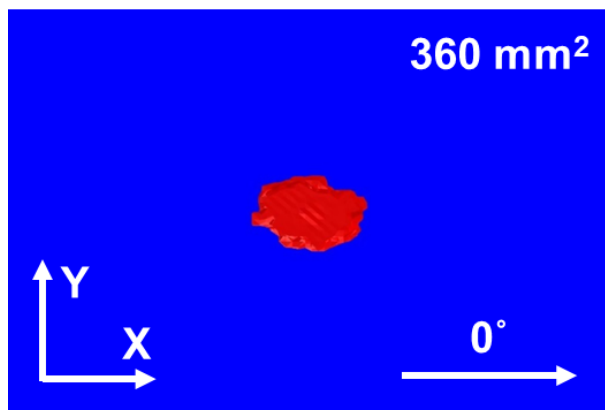

(a)
3-D Elastic model

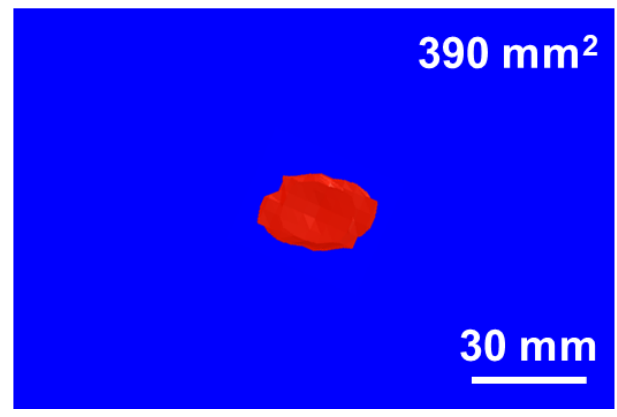

(b)

Fig. 14. Predictions for the CF/PEEK composite for the interlaminar cracking, i.e. delamination, areal footprints at an impact energy of $10.5 \mathrm{~J}$ from: (a) the 3-D EP model and (b) the 3-D Elastic only model at an impact energy of $10.5 \mathrm{~J}$. 


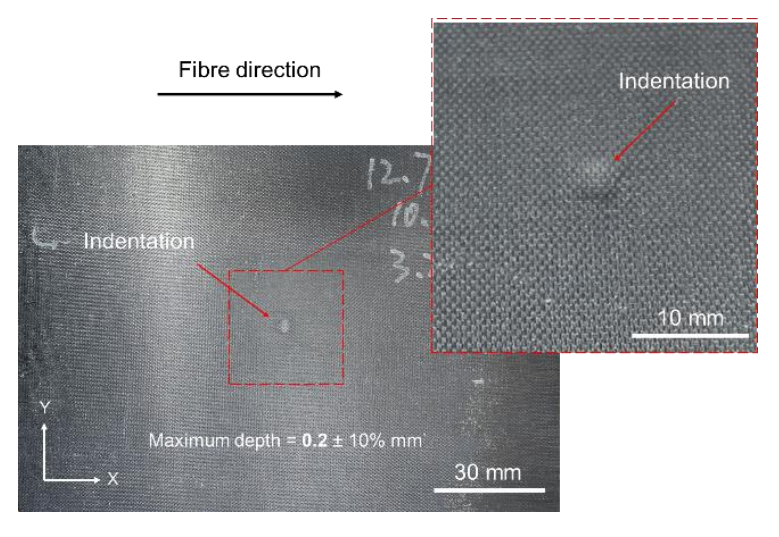

(a)

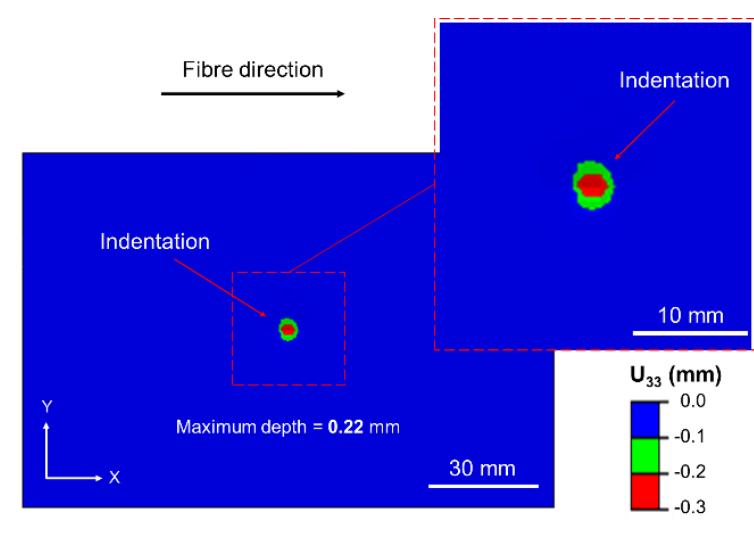

(b)

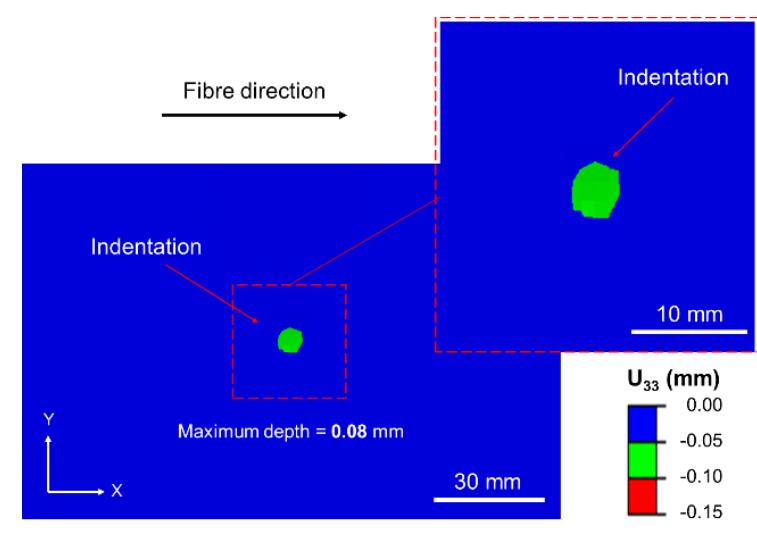

(c)

Fig. 15. Plan view of the permanent indentation of the CF/PEEK composite specimen from: (a) the experiments, (b) the 3-D EP model and (c) the 3-D Elastic only model using an impact energy of $10.5 \mathrm{~J}$. (In (a) and (b) the scale bar gives the predicted displacement, $\mathrm{U}_{33}$, in the through-thickness direction.)

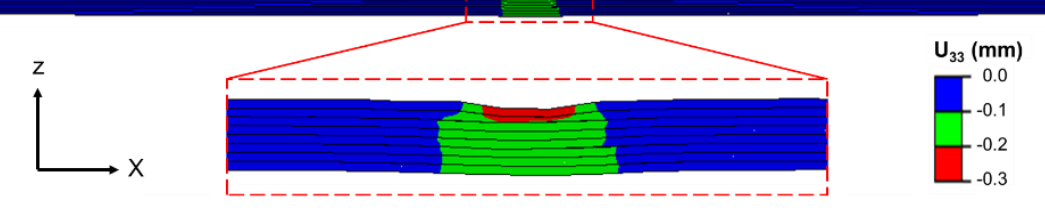

(a)

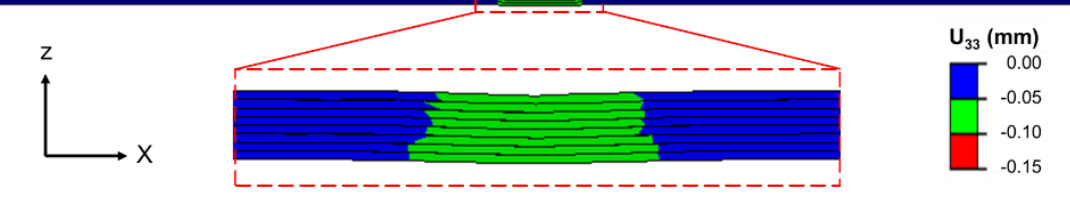

(b)

Fig. 16. Side view of the permanent indentation of the CF/PEEK composite specimen from: (a) the 3-D EP model and (b) the 3-D Elastic only model using an impact energy of $10.5 \mathrm{~J}$. (In (a) and (b) the scale bar gives the predicted displacement, $\mathrm{U}_{33}$, in the through-thickness direction.) 


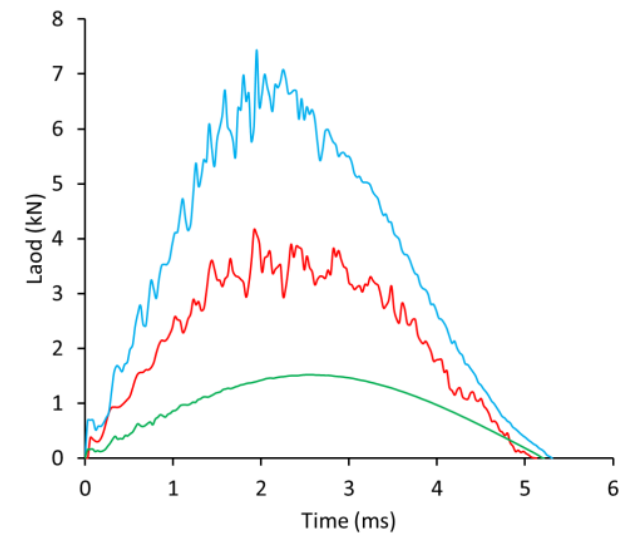

(a)

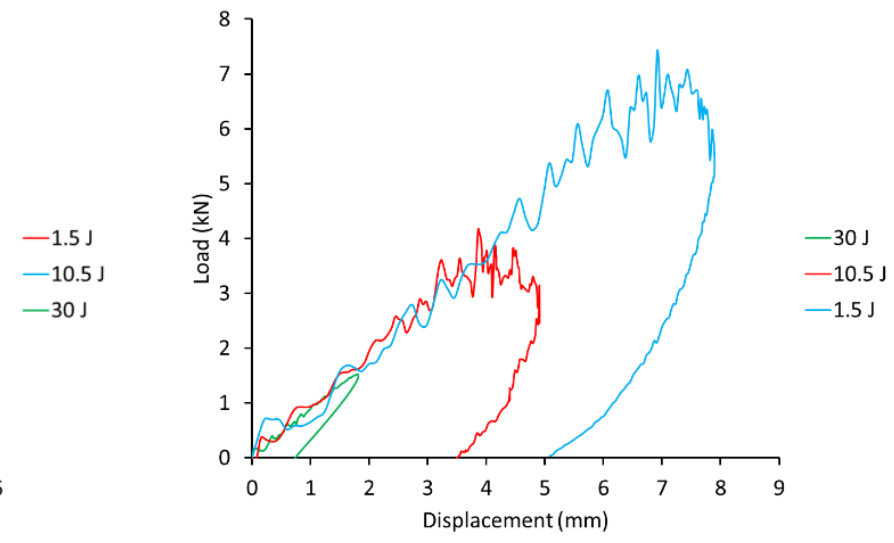

(b)

Fig. 17. Predictions for the CF/PEEK composite specimens from the 3-D EP model at impact energies of $1.5,10.5 \mathrm{~J}$ and $30 \mathrm{~J}$ : (a) load versus time traces and (b) load versus displacement traces.

$1.5 \mathrm{~J}$

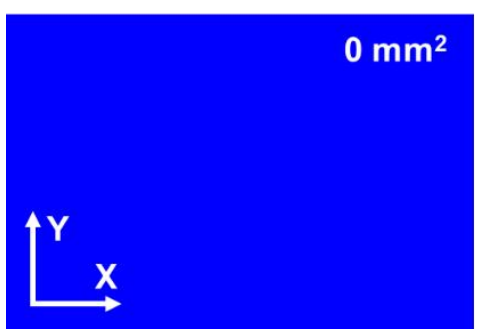

$10.5 \mathrm{~J}$

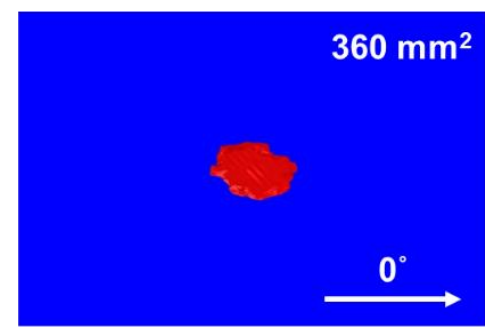

$30 \mathrm{~J}$

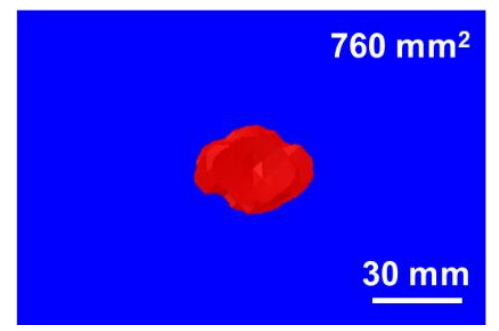

Fig. 18. Predictions for the CF/PEEK composite specimens from the 3-D EP model of the interlaminar cracking, i.e. delamination, areal footprints at impact energies of $1.5,10.5 \mathrm{~J}$ and $30 \mathrm{~J}$. 


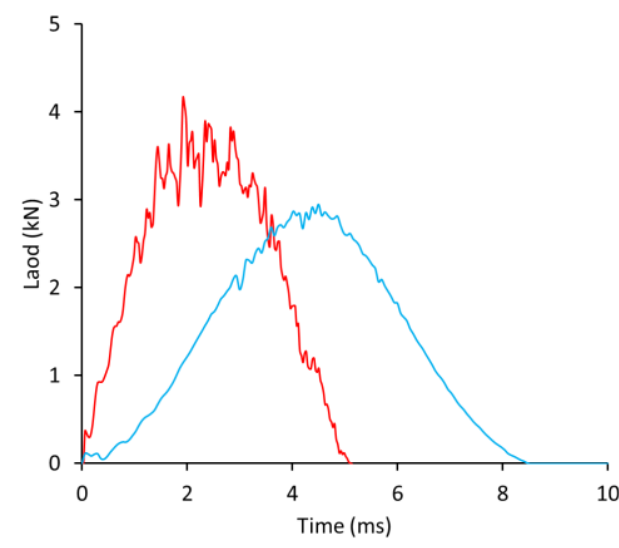

(a)

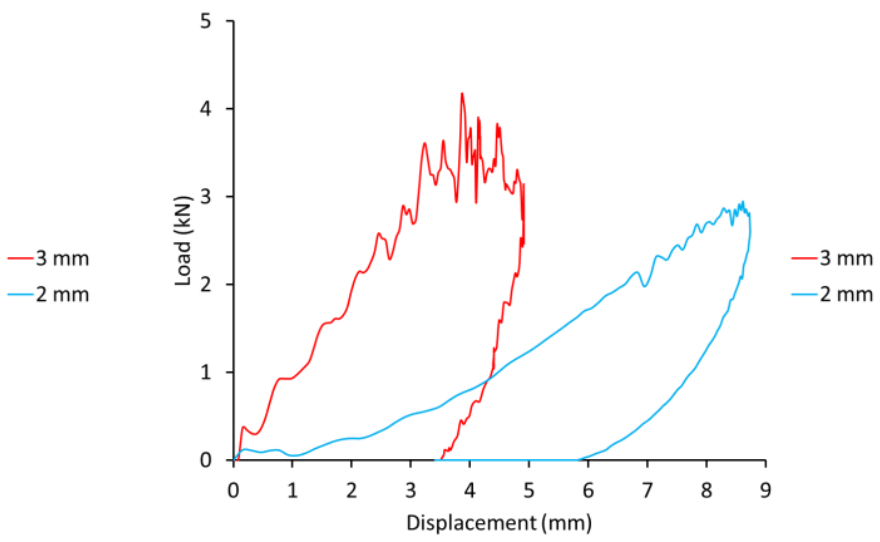

(b)

Fig. 19. Predicted (a) load versus time and (b) load versus displacement curves for the CF/PEEK composite from the 3-D EP model at an impact energy of $10.5 \mathrm{~J}$ for two different thickness of the CFRP composite specimen.

\section{$3 \mathrm{~mm}$ thick specimen}

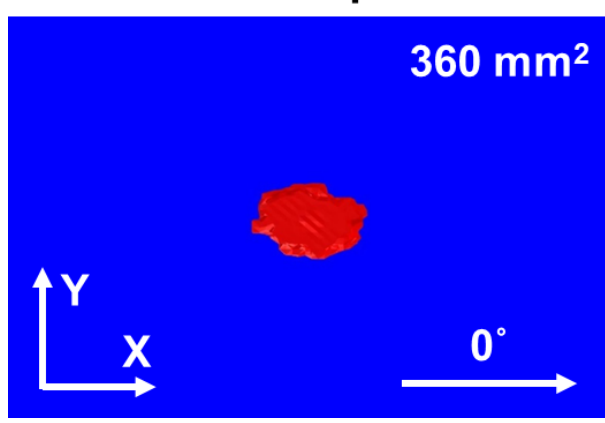

(a)

\section{$2 \mathrm{~mm}$ thick specimen}

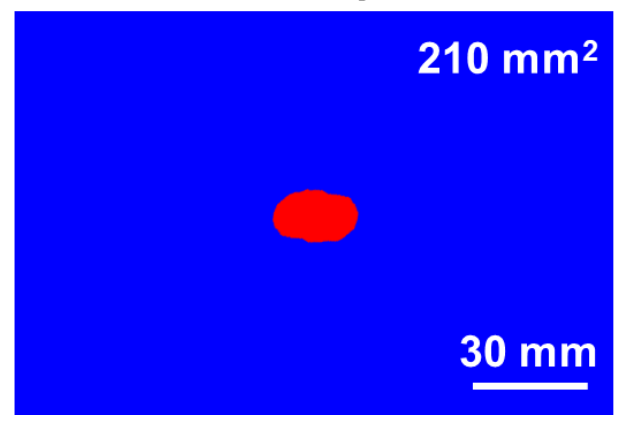

(b)

Fig. 20. Predictions for the CF/PEEK composite from the 3-D EP model of the interlaminar cracking, i.e. delamination, areal footprints at an impact energy of $10.5 \mathrm{~J}$ for two different thickness of the CFRP composite specimen. 
Table 1

The mathematical definitions for the initiation of intralaminar damage.

Damage induced by Criteria for damage initiation

Longitudinal tensile stresses

$F_{1 T}=\left(\frac{\sigma_{11}}{S_{1 t}}\right)^{2}+\frac{\tau_{12}^{2}+\tau_{13}^{2}}{S_{12}^{2}}$ for $\sigma_{11} \geq 0$

Longitudinal compressive stresses

$F_{1 C}=\left(\frac{\sigma_{11}}{S_{1 c}}\right)^{2}$ for $\sigma_{11}<0$

Transverse tensile stresses

$F_{2 T}=\frac{\sigma_{22}}{S_{2 t}}+\left(\frac{E_{22}}{2 G_{12}}\right)^{2}\left(\frac{\tau_{12}}{S_{2 t}}\right)^{2}+\left(\frac{E_{22}}{2 G_{23}}\right)^{2}\left(\frac{\tau_{23}}{S_{2 t}}\right)^{2}$

for $\left|\sigma_{22}\right| \geq\left|\tau_{12}\left(\tau_{23}\right)\right|$ and $\sigma_{22} \geq 0$

Transverse compressive stresses

$F_{2 C}=\left(\frac{\sigma_{22}}{S_{2 c}}\right)^{2}+\left(\frac{E_{22}}{G_{12}}\right)^{2}\left(\frac{\tau_{12}}{S_{2 c}}\right)^{2}+\left(\frac{E_{22}}{G_{23}}\right)^{2}\left(\frac{\tau_{23}}{S_{2 c}}\right)^{2}$

for $\left|\sigma_{22}\right| \geq\left|\tau_{12}\left(\tau_{23}\right)\right|$ and $\sigma_{22}<0$

$F_{2 S}=\left(\frac{\tau_{12}}{S_{12}}\right)^{2}+\left(\frac{\tau_{23}}{S_{23}}\right)^{2}+\frac{2 G_{12}}{E_{22}} \frac{\sigma_{22}}{S_{12}}$

for $\left|\sigma_{22}\right|<\left|\tau_{12}\left(\tau_{23}\right)\right|$

$F_{3 T}=\frac{\sigma_{33}}{S_{3 t}}+\left(\frac{E_{33}}{2 G_{13}}\right)^{2}\left(\frac{\tau_{13}}{S_{3 t}}\right)^{2}+\left(\frac{E_{33}}{2 G_{23}}\right)^{2}\left(\frac{\tau_{23}}{S_{3 t}}\right)^{2}$

Through-thickness tensile stresses

for $\left|\sigma_{33}\right| \geq\left|\tau_{13}\left(\tau_{23}\right)\right|$ and $\sigma_{33} \geq 0$

Through-thickness compressive stresses

$F_{3 C}=\left(\frac{\sigma_{33}}{S_{3 c}}\right)^{2}+\left(\frac{E_{33}}{G_{13}}\right)^{2}\left(\frac{\tau_{13}}{S_{3 c}}\right)^{2}+\left(\frac{E_{33}}{G_{23}}\right)^{2}\left(\frac{\tau_{23}}{S_{3 c}}\right)^{2}$

for $\left|\sigma_{33}\right| \geq\left|\tau_{13}\left(\tau_{23}\right)\right|$ and $\sigma_{33}<0$

$F_{3 S}=\left(\frac{\tau_{13}}{S_{13}}\right)^{2}+\left(\frac{\tau_{23}}{S_{23}}\right)^{2}+\frac{2 G_{13}}{E_{33}} \frac{\sigma_{33}}{S_{13}}$

for $\left|\sigma_{33}\right|<\left|\tau_{13}\left(\tau_{23}\right)\right|$ 


\section{Table 2}

Definition of the combined stresses at the initiation of intralaminar damage and final failure, $\sigma^{0}$ and $\sigma^{f}$, respectively.

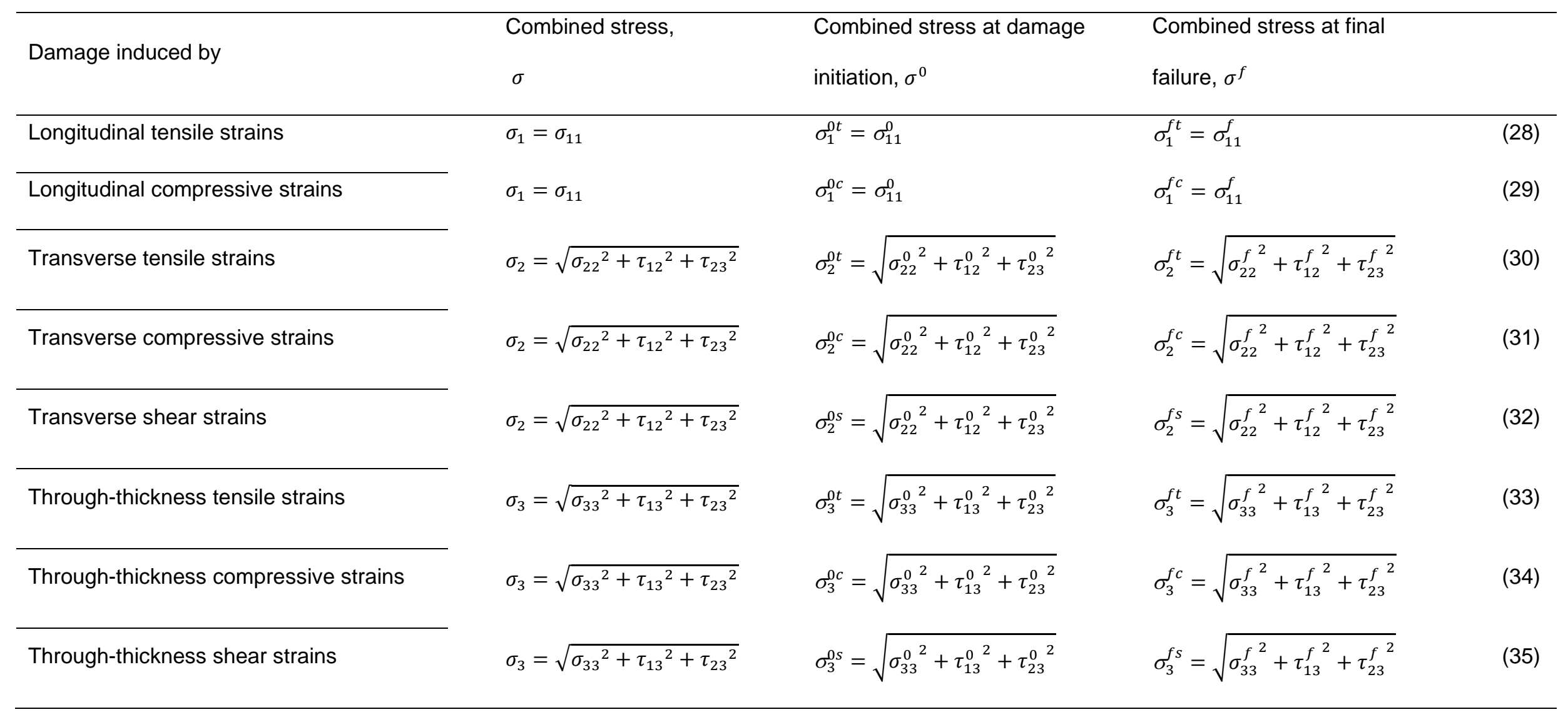




\section{Table 3}

The mathematical definitions of the combined strains and damage variables for the intralaminar damage model.

\begin{tabular}{|c|c|c|c|c|c|}
\hline Damage induced by & $\begin{array}{l}\text { Combined strain, } \\
\varepsilon\end{array}$ & $\begin{array}{l}\text { Combined strain at } \\
\text { damage initiation, } \varepsilon^{0}\end{array}$ & $\begin{array}{l}\text { Combined strain at final } \\
\text { failure, } \varepsilon^{f}\end{array}$ & $\begin{array}{l}\text { Damage variable, } \\
d\end{array}$ & \\
\hline Longitudinal tensile strains & $\varepsilon_{1}=\varepsilon_{11}$ & $\varepsilon_{1}^{0 t}=\varepsilon_{11}^{0}$ & $\varepsilon_{1}^{f t}=\varepsilon_{11}^{f}$ & $d_{1 t}=\frac{\varepsilon_{1}^{f t}\left(\varepsilon_{1}-\varepsilon_{1}^{0 t}\right)}{\varepsilon_{1}\left(\varepsilon_{1}^{f t}-\varepsilon_{1}^{0 t}\right)}$ & (36) \\
\hline $\begin{array}{l}\text { Longitudinal compressive } \\
\text { strains }\end{array}$ & $\varepsilon_{1}=\varepsilon_{11}$ & $\varepsilon_{1}^{0 c}=\varepsilon_{11}^{0}$ & $\varepsilon_{1}^{f c}=\varepsilon_{11}^{f}$ & $d_{1 c}=\frac{\varepsilon_{1}^{f c}\left(\varepsilon_{1}-\varepsilon_{1}^{0 c}\right)}{\varepsilon_{1}\left(\varepsilon_{1}^{f c}-\varepsilon_{1}^{0 c}\right)}$ & (37) \\
\hline Transverse tensile strains & $\varepsilon_{2}=\sqrt{\varepsilon_{22}^{2}+\gamma_{12}^{2}+\gamma_{23}^{2}}$ & $\varepsilon_{2}^{0 t}=\sqrt{\varepsilon_{22}^{0}{ }^{2}+\gamma_{12}^{0}{ }^{2}+\gamma_{23}^{0}{ }^{2}}$ & $\varepsilon_{2}^{f t}=\sqrt{\varepsilon_{22}^{f^{2}}+\gamma_{12}^{f^{2}}+\gamma_{23}^{f^{2}}}$ & $d_{2 t}=\frac{\left(\varepsilon_{2}^{f t}-\varepsilon_{2 p}\right)\left(\varepsilon_{2}-\varepsilon_{2}^{0 t}\right)}{\left(\varepsilon_{2}-\varepsilon_{2 p}\right)\left(\varepsilon_{2}^{f t}-\varepsilon_{2}^{0 t}\right)}$ & (38) \\
\hline Transverse compressive strains & $\varepsilon_{2}=\sqrt{\varepsilon_{22}{ }^{2}+\gamma_{12}{ }^{2}+\gamma_{23}{ }^{2}}$ & $\varepsilon_{2}^{0 c}=\sqrt{\varepsilon_{22}^{0}}{ }^{2}+{\gamma_{12}^{0}}^{2}+{\gamma_{23}^{0}}^{2}$ & $\varepsilon_{2}^{f c}=\sqrt{\varepsilon_{22}^{f^{2}}+\gamma_{12}^{f^{2}}+\gamma_{23}^{f^{2}}}$ & $d_{2 c}=\frac{\left(\varepsilon_{2}^{f c}-\varepsilon_{2 p}\right)\left(\varepsilon_{2}-\varepsilon_{2}^{0 c}\right)}{\left(\varepsilon_{2}-\varepsilon_{2 p}\right)\left(\varepsilon_{2}^{f c}-\varepsilon_{2}^{0 c}\right)}$ & (39) \\
\hline $\begin{array}{l}\text { Through-thickness compressive } \\
\text { strains }\end{array}$ & $\varepsilon_{3}=\sqrt{\varepsilon_{33}^{2}+\gamma_{13}{ }^{2}+\gamma_{23}{ }^{2}}$ & $\varepsilon_{3}^{0 c}=\sqrt{\varepsilon_{33}^{0^{2}}+\gamma_{13}^{0^{2}}+{\gamma_{23}^{0}}^{2}}$ & $\varepsilon_{3}^{f c}=\sqrt{\varepsilon_{33}^{f^{2}}+\gamma_{13}^{f^{2}}+\gamma_{23}^{f^{2}}}$ & $d_{3 c}=\frac{\left(\varepsilon_{3}^{f c}-\varepsilon_{3 p}\right)\left(\varepsilon_{3}-\varepsilon_{3}^{0 c}\right)}{\left(\varepsilon_{3}-\varepsilon_{3 p}\right)\left(\varepsilon_{3}^{f c}-\varepsilon_{3}^{0 c}\right)}$ & (42) \\
\hline Through-thickness shear strains & $\varepsilon_{3}=\sqrt{\varepsilon_{33}{ }^{2}+\gamma_{13}{ }^{2}+\gamma_{23}{ }^{2}}$ & $\varepsilon_{3}^{0 s}=\sqrt{\varepsilon_{33}^{0}{ }^{2}+\gamma_{13}^{0^{2}}+{\gamma_{23}^{0}}^{2}}$ & $\varepsilon_{3}^{f s}=\sqrt{\varepsilon_{33}^{f^{2}}+\gamma_{13}^{f^{2}}+\gamma_{23}^{f^{2}}}$ & $d_{3 s}=\frac{\left(\varepsilon_{3}^{f s}-\varepsilon_{3 p}\right)\left(\varepsilon_{3}-\varepsilon_{3}^{0 s}\right)}{\left(\varepsilon_{3}-\varepsilon_{3 p}\right)\left(\varepsilon_{3}^{f s}-\varepsilon_{3}^{0 s}\right)}$ & (43) \\
\hline
\end{tabular}




\section{Table 4}

Properties of the unidirectional ply of the composite materials $[21,48,52,53,62]$.

\begin{tabular}{|c|c|c|}
\hline Property & CF/PEEK & CF/Epoxy \\
\hline \multirow{2}{*}{ Moduli (GPa) } & $E_{11}=127 ; E_{22}=E_{33}=10.3$ & $E_{11}=130 ; E_{22}=E_{33}=7.7$ \\
\hline & $G_{23}=5.7 ; G_{12}=G_{13}=5.7$ & $G_{23}=3.8 ; G_{12}=G_{13}=4.8$ \\
\hline Poisson`s ratio & $v_{23}=0.3 ; v_{12}=v_{13}=0.3$ & $v_{23}=0.33 ; v_{12}=v_{13}=0.3$ \\
\hline \multirow{3}{*}{ Strength, $S$, values (MPa) } & $S_{1 t}=2070 ; S_{2 t}=S_{3 t}=85$ & $S_{1 t}=1950 ; S_{2 t}=S_{3 t}=75$ \\
\hline & $S_{1 c}=1360 ; S_{2 c}=S_{3 c}=276$ & $S_{1 c}=1015 ; S_{2 c}=S_{3 c}=220$ \\
\hline & $S_{12}=S_{13}=S_{23}=186$ & $S_{12}=S_{13}=S_{23}=150$ \\
\hline \multirow{3}{*}{$\begin{array}{l}\text { Intralaminar ply fracture } \\
\text { energies }\left(\mathrm{kJ} / \mathrm{m}^{2}\right)\end{array}$} & $\left.G_{I c}\right|_{f t}=218 ;\left.G_{I c}\right|_{f c}=104$ & $\left.G_{I c}\right|_{f t}=133 ;\left.G_{I c}\right|_{f c}=40$ \\
\hline & $\left.G_{I c}\right|_{m t}=1.7 ;\left.G_{I c}\right|_{m c}=2.0$ & $\left.G_{I c}\right|_{m t}=0.5 ;\left.G_{I c}\right|_{m c}=1.6$ \\
\hline & $\left.G_{I I c}\right|_{m s}=2.0$ & $\left.G_{I I c}\right|_{m s}=1.6$ \\
\hline $\begin{array}{l}\text { Interlaminar fracture } \\
\text { energies }\left(\mathrm{kJ} / \mathrm{m}^{2}\right)\end{array}$ & $G_{I C}=1.7 ; G_{I I C}=2.0$ & $G_{I C}=0.5 ; G_{I I C}=1.6$ \\
\hline $\begin{array}{l}\text { Benzeggagh-Kenane } \\
\text { exponent }\end{array}$ & $\eta=1.09$ & $\eta=1.45$ \\
\hline Cohesive strengths (MPa) & $t_{33}^{0}=43.0 ; t_{31}^{0}=t_{32}^{0}=50.0$ & $t_{33}^{0}=43.0 ; t_{31}^{0}=t_{32}^{0}=50.0$ \\
\hline $\begin{array}{l}\text { Initial cohesive law stiffness } \\
(\mathrm{MPa} / \mathrm{mm})\end{array}$ & $k_{i}=6.4 \times 10^{5}$ & $k_{i}=6.4 \times 10^{5}$ \\
\hline EP model: coefficient, $a_{66}$, & $a_{66}=1.5$ & $a_{66}=2.7$ \\
\hline and material constants, $A$ & $A=3.06 \times 10^{-19} \mathrm{MPa}^{-n}$ & $A=3.14 \times 10^{-13} \mathrm{MPa}^{-n}$ \\
\hline and $n$ & $n=7.5$ & $n=4.19$ \\
\hline
\end{tabular}




\section{Table 5}

Comparison of the experimental and predicted results for the CF/PEEK composite tested at impact energies of $4.5 \mathrm{~J}, 7.5 \mathrm{~J}$ and $10.5 \mathrm{~J}$. (The impact velocity used is also shown. The error given is the coefficient of variation from the replicate experiments.)

\begin{tabular}{|c|c|c|c|c|c|c|}
\hline & \multicolumn{2}{|c|}{$4.5 \mathrm{~J}\left(1.68 \mathrm{~m} \cdot \mathrm{s}^{-1}\right)$} & \multicolumn{2}{|c|}{$7.5 \mathrm{~J}\left(2.16{\mathrm{~m} . \mathrm{s}^{-1}}^{-1}\right.$} & \multicolumn{2}{|c|}{$10.5 \mathrm{~J}\left(2.56{\left.\mathrm{~m} . \mathrm{s}^{-1}\right)}\right.$} \\
\hline & Experiment & Simulation & Experiment & Simulation & Experiment & Simulation \\
\hline Maximum load (kN) & $3.1 \pm 7 \%$ & 2.9 & $3.6 \pm 4 \%$ & 3.7 & $3.9 \pm 3 \%$ & 4.2 \\
\hline Impact duration time (ms) & $5.2 \pm 2 \%$ & 5.1 & $5.4 \pm 2 \%$ & 5.2 & $5.2 \pm 2 \%$ & 5.1 \\
\hline $\begin{array}{l}\text { Maximum out-of-plane } \\
\text { displacement }(\mathrm{mm})\end{array}$ & $3.0 \pm 1 \%$ & 3.1 & $4.0 \pm 1 \%$ & 3.9 & $4.8 \pm 2 \%$ & 4.9 \\
\hline $\begin{array}{l}\text { Total energy } \\
\text { dissipation (J) }\end{array}$ & $2.1 \pm 9 \%$ & 1.9 & $5 \pm 6 \%$ & 4.7 & $8.8 \pm 5 \%$ & 8.2 \\
\hline $\begin{array}{l}\text { Average area of the } \\
\text { delamination footprint } \\
\left(\mathrm{mm}^{2}\right)\end{array}$ & $0 \pm 0 \%$ & 110 & $274 \pm 11 \%$ & 270 & $335 \pm 5 \%$ & 360 \\
\hline
\end{tabular}

\section{Table 6}

Comparison of the experimental and predicted results for the CF/Epoxy composite tested at impact energies of $4.5 \mathrm{~J}, 7.5 \mathrm{~J}$ and $10.5 \mathrm{~J}$. (The impact velocity used is also shown. The error given is the coefficient of variation from the replicate experiments.)

\begin{tabular}{|c|c|c|c|c|c|c|}
\hline & \multicolumn{2}{|c|}{$4.5 \mathrm{~J}\left(1.68 \mathrm{~m} . \mathrm{s}^{-1}\right)$} & \multicolumn{2}{|c|}{$7.5 \mathrm{~J}\left(2.16 \mathrm{~m} . \mathrm{s}^{-1}\right)$} & \multicolumn{2}{|c|}{$10.5 \mathrm{~J}\left(2.56 \mathrm{~m} . \mathrm{s}^{-1}\right)$} \\
\hline & Experiment & Simulation & Experiment & Simulation & Experiment & Simulation \\
\hline Maximum load $(\mathrm{kN})$ & $2.8 \pm 6 \%$ & 3.0 & $3.4 \pm 2 \%$ & 3.6 & $3.9 \pm 2 \%$ & 4.0 \\
\hline Impact duration time (ms) & $5.9 \pm 1 \%$ & 5.7 & $5.5 \pm 2 \%$ & 5.6 & $5.5 \pm 2 \%$ & 5.3 \\
\hline $\begin{array}{l}\text { Maximum out-of-plane } \\
\text { displacement }(\mathrm{mm})\end{array}$ & $3.2 \pm 1 \%$ & 3.1 & $4.1 \pm 1 \%$ & 4.2 & $4.9 \pm 1 \%$ & 4.8 \\
\hline $\begin{array}{l}\text { Total energy } \\
\text { dissipation (J) }\end{array}$ & $1.6 \pm 8 \%$ & 1.5 & $4.8 \pm 5 \%$ & 4.5 & $8.1 \pm 3 \%$ & 7.9 \\
\hline $\begin{array}{l}\text { Average area of the } \\
\text { delamination footprint } \\
\left(\mathrm{mm}^{2}\right)\end{array}$ & $267 \pm 6 \%$ & 270 & $395 \pm 3 \%$ & 410 & $517 \pm 6 \%$ & 560 \\
\hline
\end{tabular}

